\title{
Diffusion MRI in Early Cancer Therapeutic Response Assessment
}

Craig J. Galbán PhD ${ }^{1}$, Benjamin A. Hoff $\mathrm{PhD}^{1}$, Thomas L. Chenevert ${ }^{1}$ and Brian D. Ross $\mathrm{PhD}^{1}$

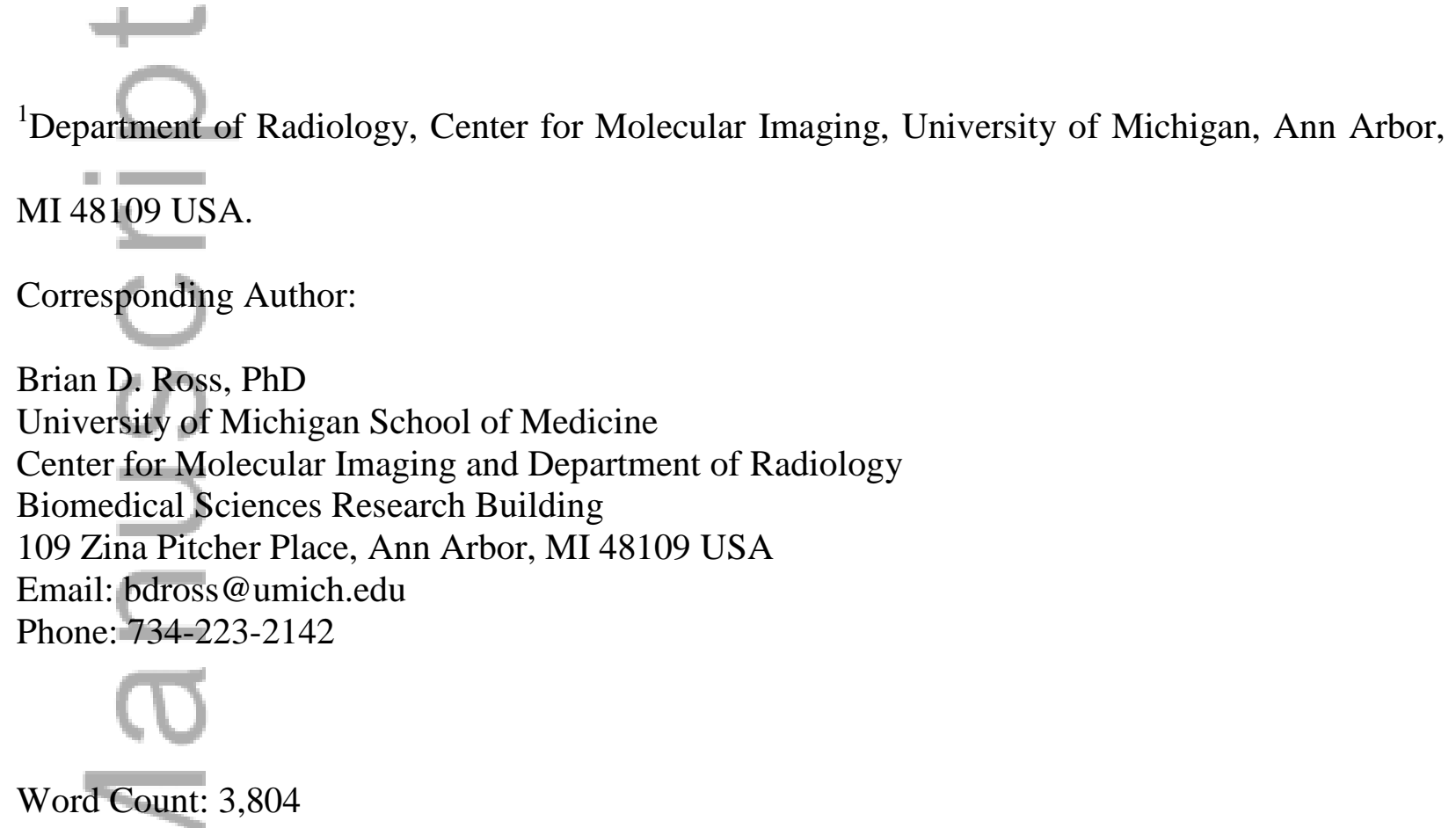

Key Words: review article, cancer treatment response, imaging biomarker, functional diffusion map, diffusion-weighted MRI,

Abbreviations: Diffusion-weighted MRI (DW-MRI), apparent diffusion coefficient (ADC), whole-body diffusion weighted MRI (wb-DWI), functional diffusion map (fDM)

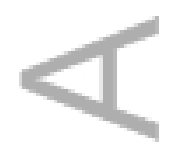

This is the author manuscript accepted for publication and has undergone full peer review but has not been through the copyediting, typesetting, pagination and proofreading process, which may lead to differences between this version and the Version of Record. Please cite this article as doi: $10.1002 / \mathrm{nbm} .3458$

This article is protected by copyright. All rights reserved. 


\section{ABSTRACT:}

Imaging biomarkers for predictive assessment of treatment response in oncology patient earlier than standard tumor volumetric metrics would provide new opportunities to individualize therapy. Diffusion-weighted MRI (DW-MRI), highly sensitive to microenvironmental alterations at the cellular level, has been extensively evaluated as a technique for generating quantitative and early imaging biomarkers of therapeutic response and clinical outcome. First demonstrated in a rodent tumor model, subsequent studies have shown that DW-MRI can be applied to many different solid tumors for detecting changes in cellularity as indirectly measured by an increase in the apparent diffusion coefficient (ADC) of water molecules within the lesion. Introducing quantitative DW-MRI into the treatment management of cancer patients may aid physicians in individualizing therapy thereby minimizing unnecessary systemic toxicity associated with ineffective therapies, save valuable time, reduce patient care costs and ultimately improve clinical outcome. This review covers the theoretical basis behind the application of DW-MRI to monitor therapeutic response in cancer, analytical techniques as well as the results from various clinical studies that have demonstrated the efficacy of DW-MRI for prediction of cancer treatment response.

This article is protected by copyright. All rights reserved. 


\section{INTRODUCTION:}

\section{MONITORING CANCER TREATMENT RESPONSE}

Image-based assessment of cancer treatment response continues to be an active area of research with advances in medical imaging instrumentation providing opportunities to fundamentally change the clinical management of cancer patients. Magnetic resonance imaging (MRI) represents a key modality that has found use in diagnosis, treatment planning, and assessment of response and recurrence of solid malignancies. By providing high spatial resolution and soft tissue contrast, MRI allows exquisite non-invasive radiographic detection of tumor location while also providing for determination of tumor number and dimensions.

Computed tomography, and soon after MRI, have been used since the 1960s to measure gross changes in tumor volume following a therapeutic intervention (1). Although there have been advancements in quantitative imaging techniques, such as DW-MRI, DCE-MRI and FDGPET, standard practice for patient management and clinical trials continues to employ anatomical images to assess tumor response to treatment (2-4). The WHO and the Response Evaluation Criteria in Solid Tumors (RECIST) have proposed guidelines primarily based on a single linear summation of specific lesions where monitoring morphological changes in tumor volume allows for routine measurements for cancer response assessment. Nevertheless, there continues to be growing concerns regarding the adequacy of these criteria as some treatments, such as molecularly targeted agents, may provide therapeutic benefit without significantly reducing the tumor volume (5-7). These concerns underscore the urgency for development and 
implementation of reliable response imaging biomarkers or surrogates that can detect response to treatment earlier than current methodologies $(8,9)$.

\section{GENERAL CONCEPTS IN DIFFUSION}

The first diffusion MR sequence was demonstrated in 1965 by Stejskal and Tanner (10), and by the 1980s diffusion-weighted MRI of in vivo systems was reported (11-13). Since then reviews have been generated on the principle and technical aspects of this MR technique as well as consensus recommendations using diffusion imaging as a response metric for treatment assessment (14-16). Molecular diffusion is the thermally driven random translational motion of molecules in media, which is referred to as Brownian motion. Key factors that exert their influence on the mobility of a diffusing molecule include media viscosity, temperature, and its molecular mass. Diffusion is not a magnetization-related process like, for example, T1 and T2 magnetization relaxation that drives conventional MRI contrast. Nevertheless, MRI can be used to noninvasively quantify (image) water diffusion values spatially in vivo. This is accomplished in part through the use of magnetic gradients that allow for the "encoding” of initial locations of constituent water molecules in the tissue. Following a brief interval, the same gradients are used to "decode" the molecular locations. For those water molecules in which displacement has occurred during the time interval, decoding will be incomplete, resulting in the loss of signal through spin dephasing. The dephasing amount increases in proportion to the distance translated between encode/decode diffusion gradient pulses. Highly mobile water molecules will have more attenuation of the signal relative to water in a more restricted/cellular tissue environments. Determination of the degree of signal loss at various diffusion gradient settings provides for the 
ability to calculate molecular mobility in complex systems, such as tumor tissue. However, because tumor tissue is composed of water located in a highly complex microenvironment, the concept of a single diffusion coefficient is not valid and as such is reported as an "apparent diffusion coefficient” (ADC) $(13,14)$. ADC measurements can be used to assess a myriad of properties that impede molecular motions including cell membrane integrity, cell density, $=$ interactions with macromolecules, as well as processes that enhance mobility via active transport, convective motion, and perfusion.

The ability of water to sample its surrounding environment is the foundation behind its efficacy as a measure of tumor response to cancer. The thermal, i.e. Brownian, motion of free water at body temperature $\left(\sim 35^{\circ} \mathrm{C}\right)$ is approximately $3 \times 10^{-3} \mathrm{~mm}^{2} / \mathrm{s}$. Clinical DW-MRI sequences typically have a bipolar gradient interval around 50ms, resulting in the displacement of free water molecules of $30 \mu \mathrm{m}$. By applying these motion sensitive gradients, water molecules can be exploited to sample the microenvironment of biological systems well within the resolution of the MRI sequence. Structures within the solid tumor that are sampled by water molecules may include the tumor cells membranes, organelles, myelin layers, and macromolecules as well as additional cellular and subcellular entities all of which are on the order of micrometers. Transient association of water with large, slow-moving macromolecules and cell membranes that result in water binding, as well as impediment by membranes and other structures, effectively reduce water mobility to an ADC lower than free water diffusion. The greater the bulk density of structures within a tumor tissue that impedes water mobility, the lower the ADC value for that tumor. As such ADC is considered a noninvasive imaging biomarker of 
cellularity or cell density. However, if two tissues have different ADC values, the lower ADC tissue may not necessarily have the greater number of cells per unit volume. Other factors that make up the microenvironment (e.g. cell size, viscosity, vasculature, extracellular matrix and permeability) also affect water mobility and ADC. Within a given tissue or cell type, ADC is useful as an indicator of the relative cellularity, such as in the evolution of tumor over time following therapy. Cellular alterations due to disease or intervention, as well as changes in cellular organization or integrity of cellular elements, are available for study by diffusion imaging.

Water diffusion on the order of cellular distances is measurable in spite of the presence of other much larger physiologic motions. A single-shot echo-planar imaging (EPI) approach (17) is the standard imaging sequence for acquiring diffusion weighted imaging. EPI. By acquiring the entire set of echoes for an image within one single scanning period, respiratory bulk tissue motion, which would overwhelm the measurement of molecular motion, is essentially eliminated. By decreasing acquisition times by a factor of 100, EPI has also allowed DW-MRI to be incorporated as a standard MRI sequence in clinical scanners and used in routine clinical scanning protocols. However, images generated by EPI are sensitive to artifacts such as distortion and signal loss owing to magnetic susceptibility. These limitations aside, EPI is the most commonly used clinical sequence combined with diffusion-sensitization gradient pulses to perform DW-MRI.

This article is protected by copyright. All rights reserved. 


\section{ADC AS A MEASURE OF TUMOR CELLULARITY}

It is traditionally viewed that as cellular density increases, the added tortuosity within the microenvironment reduces water mobility. Figure 1 illustrates the effect of an effective therapeutic agent on the water diffusivity in a solid tumor mass (18). Solid tumors typically have a mean ADC value around $1 \times 10^{-3} \mathrm{~mm}^{2} / \mathrm{s}$ (Figure 1). Following the intervention of a therapeutic agent that results in cell kill (i.e. drop in tumor cellularity), the extracellular space increases as the intracellular space diminishes (Figure 1). This results in a shift in the tumor water diffusivity to higher values in therapeutically responsive regions of the tumor. Several groups have reported the inverse relationship between ADC and cellular density (19-22). To aid in interpreting these results a biphasic model relating ADC values to cellularity was proposed where two pools of water within the tissue exist, a fast diffusion and a slow diffusion pool (23). The slow diffusion pool is proposed to consist of a water layer trapped by electrostatic forces of the cellular membranes and associated cytoskeleton. The fast diffusion pool is thought to belong to a combination of intra- and extracellular compartments that are, however, slower than free water. Both the traditional, i.e. monoexponential, and biphasic diffusion models provide for the rationale that water diffusion will decrease during cell swelling or cell proliferation and increase during treatment-induced loss of cellular viability or density. Regardless of the underlying mechanism, the fact remains that tumor diffusion values increase as tumor tissue initially progresses from a solid, cellular lesion to an acellular, necrotic tumor during successful cytotoxic therapy. This characteristic of tumor water diffusion values provides a key opportunity to use 
this biophysical and quantifiable ADC parameter as a sensitive biomarker for detecting the underlying changes of tumor cytoarchitecture associated with treatment (24).

\section{DIFFUSION IMAGING TO ASSESS TREATMENT RESPONSE}

Twenty years of research in preclinical studies have supported the notion that water diffusivity is highly dependent on the tumor microenvironment. This suggests that diffusion MR can be used to noninvasively detect cellular changes associated with treatment-induced cell killing in animal models (19,20,22,25-30). The key findings in many studies were that changes in ADC values preceded changes in tumor volume regression, as well as being treatmentindependent, and dose/efficacy-dependent. All of this supports the claim that this imaging biomarker may indeed be used as an early surrogate for assessment of treatment outcome.

Diffusion MRI as a method for therapeutic response assessment in the clinic was first demonstrated in glioma patients (21). Tumors treated with radiation with or without chemotherapy demonstrated an increase in ADC values from baseline. The magnitude of change in ADC values correlated to cellularity in the tumor mass albeit in a pilot study. Through advances in rf coil design, parallel imaging and rapid pulse sequencing diffusion MRI as a biomarker of treatment response has been demonstrated in breast cancer (31-38) liver cancer (3947), prostate cancer $(34,48)$, rectal cancer $(49-57)$, lymphomas $(20,58-63)$, head and neck cancer $(64,65)$ and metastases $(29,33,37,66-72)$. Results from clinical studies have shown a significant difference in the mean $\mathrm{ADC}$ values between patients responding to treatment in comparison to patients that were determined to be nonresponsive to treatment.

This article is protected by copyright. All rights reserved. 
An example of the clinical application of DW-MRI for assessment of early treatment response was reported in stage II/III breast cancer patients treated with neoadjuvant chemotherapy (NAC) (73). Presented in Figure 2 are representative slices of ADC tumor maps from two breast cancer patients who underwent two cycles of neoadjuvant therapy. The first patient revealed an increase in tumor diffusion values (Figure 2A), indicating cell killing had occurred with no significant reduction in tumor size (Figure 2B). Following the second cycle of treatment, a significant decrease in tumor volume was noted. In the second breast cancer patient, ADC yalues remained stable over the treatment period and the patient was subsequently classified as non-pCR (Figure 2C, D). This data reveals the tremendous potential that DW-MRI has for early monitoring of cancer treatment response.

While an initial increase in tumor ADC values during treatment is typically associated with cell death, a subsequent drop in tumor ADC values may occur indicating tumor regrowth or possibly fibrosis. This present understanding is supported by findings in recurrent high-grade gliomas and osteosarcomas where lower ADC values are observed in viable tumor and higher ADC values in regions of necrosis following treatment $(74,75)$. Thus ADC values in the context of determining treatment response should likely be limited to early time intervals post-treatment initiation due to the more complex late-stage cellular processes that may complicate interpretation.

Metastatic lesions pose a very distinct problem for treatment management of cancer patients with disseminated disease. In many cases, primary tumors that have metastasized will seed osseous regions. Although bone scans using Tc99m-SPECT imaging is standard clinical 
practice for diagnosing metastatic cancer to the bone, RECIST continues to label bony tumors as "non-measureable" due to the complex metabolic state of the bone interacting with the tumor. DW-MRI with its high soft tissue contrast and resolution has been shown to be highly sensitive to tumor response to therapy irrespective of bone turnover. In a preliminary pilot study, Lee and colleagues first demonstrated the utility of DW-MRI for therapeutic response assessment in two $=$ patients with metastatic prostate cancer to the bone (29), which was later validated in a large data set by Reischauer and colleagues (76).

\section{WHOLE-BODY DW-MRI}

Although the aforementioned studies $(29,76)$ focused only on treatment response on individual tumors, advances in whole body (wb) diffusion-weighted MRI may allow for multiple lesions to be monitored simultaneously $(77,78)$. This is illustrated in the work by Horger and colleagues were 20 lymphoma patients undergoing systemic therapy are monitored using wbDW-MRI (59). Figure 3 demonstrates the sensitivity of wbDW-MRI at detecting variations in therapeutic response in a single patient. Multi-focal lesions within the patient were found to have increased ADC values, suggesting cell kill occurred following treatment as depicted in these inverted gray-scale images (arrows). In contrast, the large tumor in the pelvic node (arrowhead) revealed a stable ADC value. Through the use of wbDW-MRI, early response assessment can now be obtained over multiple lesions but at a price of reduced spatial resolution. 


\section{ANOMALIES IN REPORTED DIFFUSION VALUES FOR TUMOR RESPONSE}

Most studies have reported that tumor water ADC values typically increase following successful intervention of solid tumors. Although this trend appears to be the norm there have been cases where a decrease, rather than an increase, in ADC measurements were reported to correlate with positive response (54,79-81). As the tumor mass will respond dynamically throughout the course of fractionated therapies consequently, timing of the acquired DW-MRI measurement may impact the findings. For example, two studies that investigated the efficacy of DW-MRI on treated rectal cancer $(54,80)$ showed a brief, transient increase in ADC in the first week post-treatment initiation. Subsequently, a decrease in ADC was observed over the next several weeks. Histology confirmed that chemoradiation of rectal carcinoma resulted in increased interstitial fibrosis which may have an effect of reducing ADC values in those tumor regions (54). The authors had also drawn attention that regions of obvious necrosis as observed by MRI within the tumor mass were not included in the volume of interest prescribed over the tumor mass. Omission of the necrotic regions would bias the measurement to lower ADC values. Therefore, the reported decreased ADC values that correlated with response appear to be primarily related to the timing of the measurement as well as fibrotic formation following tumor cell death.

\section{SPATIAL HETEROGENEITY IN TUMOR RESPONSE}

Spatial heterogeneity in tumor response is a major confounding factor in assigning a

single indicator to a patient. A given lesion often contains wide gradations of viable cellularity and necrosis, and the response of tumor subregions to treatment can be nonuniform and 
dependent on many factors. Histogram analysis of ADC values throughout the tumor is one approach to address heterogeneity $(83,84)$. Although a variety of scalar quantities are derivable from tumor ADC histogram analysis, the magnitude of regional changes may be underestimated by whole-tumor summary statistics in the presence of heterogeneous response patterns. Figure 4 from Ref (85) illustrates the affect of response heterogeneity on the tumor histogram. Using simulated data, the authors demonstrated that uniform changes in tumor ADC values result in a mean ADC that can detect alterations in tumor ADC values (Figure 4B). Although other wholetumor metrics may provide more sensitivity, such as the standard deviation for the case when regions of the tumor demonstrate increasing and decreasing ADC values from baseline (Figure 4C), one would have to know a priori the most appropriate measure. A more comprehensive evaluation has been performed on the efficacy of histogram-based measures for therapeutic response assessment using MRI-derived blood volume maps in glioma patients (86). Although not performed using DW-MRI acquired parameters, the study observed negligible effectiveness of a variety of whole-tumor quantitative metrics at detecting tumor response at both one and three week post-treatment initiation.

An alternative image processing approach has been developed to quantify and spatially map the intrinsic treatment-associated heterogeneity of diffusion values within a tumor. This technique is referred to as functional diffusion mapping (fDM) (87). A key element of fDM is spatial registration of baseline and follow-up three-dimensional quantitative diffusion maps (i.e. ADC) into a single geometrical space. Further reading on the registration techniques and limitations for therapeutic response assessment is provided in $\operatorname{Refs}(85,88,89)$. Once registered, 
diffusion changes are measured on a voxel-by-voxel basis from spatially aligned pretreatment, and post-treatment initiation ADC maps. Tumor voxels are then classified by their extent of change in ADC. Although fDM has been initially evaluated in glioma patients (87,90-93), this technique has been applied to other tumor types $(29,65,76,85)$. Shown in Figure 5 are fDMs (also referred to as Parametric Response Mapping $\left(\mathrm{PRM}_{\mathrm{ADC}}\right)$ ) with corresponding scatter plots from head and neck squamous cell carcinoma (HNSCC) patients diagnosed as CR (Figure 5A) and PR (Figure 5B) following therapy. By analyzing the diffusion maps using fDM, heterogeneity in tumor response can be visualized with red regions denoting response (i.e. increase in ADC from baseline) versus stable and decreased ADC regions depicted as green and blue, respectively. As demonstrated in a variety of tumor types, large regions of increased ADC from baseline (i.e. red voxels) were strongly correlated with treatment response irrespective of the presence of tumor regions with stable or decreasing ADC values.

\section{STANDARDIZATION AND REPEATABILITY OF ADC MEASUREMENT}

As discussed in this review the biophysical premise and technical feasibility have allowed quantitative DW-MRI to be a clinically viable technique. Nevertheless, for this imaging protocol to become routine in the management of patients and clinical trials there is a need to standardize DW-MRI acquisition schemes to account for intra and inter-vendor instrument variability(94). In an effort to bring uniformity throughout the various MRI systems, phantoms have been developed to confirm quantitative agreement across platforms. The ideal phantom must be stable throughout the imaging sequences and provide meaningful ADC measurements consistent with 
biological systems. Due to the complexity of water diffusion in living tissue, development of a phantom that is both stable and mimics all tissue properties has its difficulties. Simple fluidbased test objects are the preferred approach to phantom development using fluids that are thermally stable, readily available and safe when properly handled(95,96). In a study by Tofts and colleagues, the diffusion coefficient of 15 organic liquids were evaluated and found to stably provide repeatable ADC measurements within the relevant range of biological systems (0.36$\left.2.6 \times 10^{-3} \mathrm{~mm}^{2} \mathrm{~s}\right)(97)$. In 2011, Chenevert and colleagues reported on a temperature-controlled phantom using water cooled to near freezing(98). This phantom consisted of liquid water jacketed with ice water such that the inner chamber was cooled to $\sim 0^{\circ} \mathrm{C}$. Although water diffusivity is highly sensitive to temperature (99), jacketing the liquid water with ice allowed a stable environment with temperatures maintained for up to 4 hours and a reliable, biologically relevant ADC value $\left(\sim 1 \times 10^{-3} \mathrm{~mm}^{2} / \mathrm{s}\right)$. The availability of stable and reproducible phantoms has allowed multi-center studies to be performed demonstrating the repeatability of quantitative DWMRI across platforms $(100,101)$.

In the absence of standard DW-MRI protocol, investigators of clinical trials are employing strategies for contending with intra-instrument variability. Affectionately referred to as the "coffee-break exam", this approach acquires repeat DW-MRI examinations, minutes to hours apart, to ascertain the variability in the ADC measurement prior to therapeutic intervention. The motivation of this strategy is to characterize the noise associated with the ADC measurement for a given patient and platform in the absence of disease or treatment related changes in tumor physiology and anatomy. Various studies, just to name a few, have reported 
stable quantitative DW-MRI measurements in head and neck squamous cell carcinomas(64), hepatocellular carcinoma(102), malignant lung lesions(103), rectal cancer (104) and primary beast cancer(105). Until uniformity in DW-MRI protocols between vendors, instruments and sites is obtained, the strategy of repeat examinations prior to therapeutic intervention will help elevate some of the variability in the ADC measurement within a given instrument.

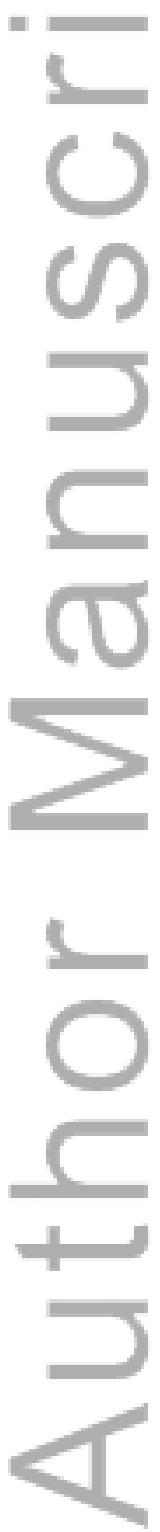

This article is protected by copyright. All rights reserved. 


\section{FUTURE DIRECTIONS}

Studies presented here support the use of DW-MRI as an early surrogate biomarker for tumor response assessment. In a growing body of literature, changes in tumor water diffusion values have been reported to correlate with response to therapy despite the diverse set of tumor types, MRI manufacturers, magnetic field strengths used to collect the data along with the varying approaches used to analyse the data sets (Figure 6, Table 2). Taken together this reveals the overall robustness of DW-MRI for oncology treatment assessment. Clinical cancer studies on the efficacy of DW-MRI as a surrogate imaging biomarker of tumor treatment response have demonstrated that treatment-induced cell death can be detected in responding tumors as an increased ADC value in those regions. Due to variability in DW-MRI acquisition and analytical post-processing protocols, efforts have solidified in the publication of a consensus paper to provide for standardization across institutions (16). In addition, temperature controlled phantoms have recently been developed to facilitate multi-center DW-MRI clinical trials $(100,101)$. These standards are needed for data acquisition, post-image processing, timing of evaluation, and the method used to generate the quantifiable metric used to report treatment response. While the momentum for using DW-MRI in the context of tumor response assessment is continuing to grow, validation of DW-MRI as a surrogate imaging biomarker of response will require a large, prospective, multi-institutional trial performed in a standardized fashion between sites. Analysis of the data could also be useful for the validation of the image post-processing software and for regulatory approval as a device. Having an FDA or European approved software package would provide additional momentum for enhancing the probability that DW- 
MRI will ultimately be incorporated into routine clinical practice for the management of cancer patients. Future opportunities in employing DW-MRI in the clinical management of cancer patients may include adaptive therapy protocols based on intra-therapy evaluation of early ADC changes during fractionated dosage schedules allowing for modification of interventions and for quantifying multi-focal disease response using wbDW-MRI (78). Finally, the recent emergence $=$ in of anticancer immunotherapies raises an urgent need for establishing radiological metrics for assessing response to such experimental interventions (106-108). Further efforts investigating advanced imaging techniques such as DW-MRI are needed to delineate its ability to provide meaningful insights into treatment responsiveness in order for it to successfully impact clinical decision making.

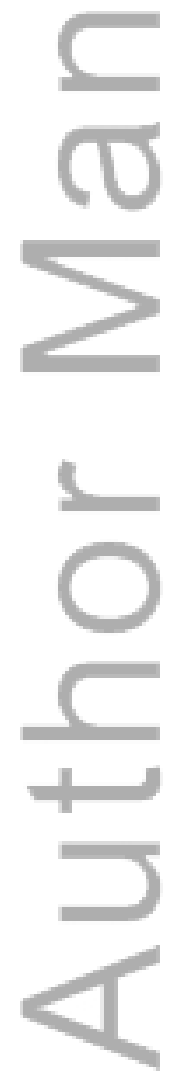

This article is protected by copyright. All rights reserved. 


\section{4 \\ ACKNOWLEDGEMENTS}

\section{$=$}

Funding support for this work was provided by National Institutes of Health grants (

P01CA085878 and U01CA166104.

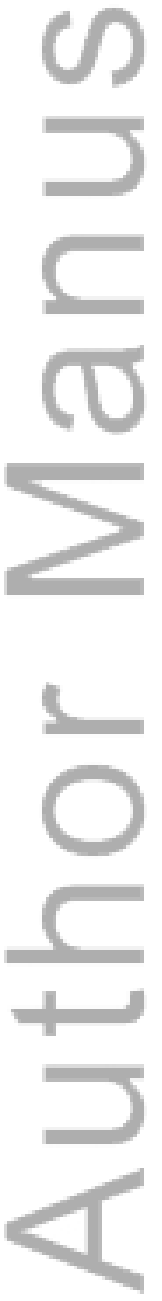

This article is protected by copyright. All rights reserved. 
Table 1

\begin{tabular}{|l|l|}
\hline Site & Reference \\
\hline Abdominal & $(109)$ \\
\hline $\begin{array}{l}\text { Acoustic } \\
\text { Neuroma }\end{array}$ & $(110)$ \\
\hline Bladder & $(111,112)$ \\
\hline Bone Marrow & $(113)$ \\
\hline Brain & $(26,87,93,114-138)$ \\
\hline Breast & $(35-38,139-152)$ \\
\hline Cervical & $(153-160)$ \\
\hline Eye & $(161,162)$ \\
\hline Leiomyoma & $(163-165)$ \\
\hline Liver & $(41,42,44,46,70,166-181)$ \\
\hline Lung & $(182-185)$ \\
\hline Lymphoma & $(186-188)$ \\
\hline Myeloma & $(189,190)$ \\
\hline Ovarian & $(191-193)$ \\
\hline Pancreas & $(194)$ \\
\hline Prostate & $(29,195-198)$ \\
\hline Rectal & $(54,79,199-207)$ \\
\hline Sarcoma & $(208-214)$ \\
\hline SCCHN & $(65,215-220)$ \\
\hline
\end{tabular}

This article is protected by copyright. All rights reserved. 


\section{FIGURE LEGENDS}

Figure 1. A schematic of changes in water diffusivity in a tumor following an effective therapeutic agent. Changes in cellularity (left) occur with increased molecular water mobility measured as an apparent diffusion coefficient (ADC; right) as a tumor responds to treatment (top to bottom). As a tumor responds to therapy, an increase in extracellular space and membrane permeability occurs which allows for increased water mobility and detected by DW-MR as an increase in ADC values. (Courtesy of Ref. (18)).

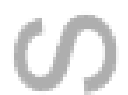

Figure 2. (A) ADC maps superimposed over the postcontrast DCE-MR images at 3 time points (pretreatment, after 1 cycle, and after all cycles of NAC) for a patient achieving pCR. The numbers for each panel represent the mean ADC values for each time point in the parametric map. (B) The difference image between precontrast and postcontrast DCE-MRI at each time point. (C) ADC maps superimposed over the postcontrast DCE-MR images at 3 time points (pretreatment, after 1 cycle, and after all cycles of NAC) for a non-pCR patient. The numbers for each panel represent the mean ADC values for each time point in the parametric map. (D) The difference image between precontrast and postcontrast DCE-MRI at each time point. (Courtesy of and adapted from Ref. (73)).

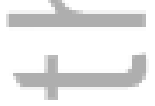

Figure 3. Whole-Body DWI is presented as an early indicator of response to systemic therapy in lymphoma patients. (A) A 48-year-old male patient diagnosed with diffuse large B-cell lymphoma obtained at baseline shows ubiquitous involvement of lymph nodes (e.g. cervical and 
retroperitoneal—small arrows) and in the axillary regions (large arrows) with marked restriction of water diffusivity. A larger pelvic node (arrowhead) is also seen left to the midline. (B) At day 7, following institution of chemotherapy with rituximab (anti-CD20 antibodies) + CHOP (cyclophospamide, hydroxydaunorubicin, vincristine, prednisolone), Whole-body DW-MR shows evident reduction in signal intensity in the cervical and retroperitoneal node regions (small arrows) and axillary region (large arrows) (from $\mathrm{ADC}=0.90 / 0.33 / 0.67 / 0.61$ to $\mathrm{ADC}=1.66 / 0.73 / 1.36 / 1.22$ ) with corresponding increase in ADC (not shown), but less marked response in the pelvic node (arrowhead) (from ADC $=0.83 / 0.51$ to $\mathrm{ADC}=1.12 / 0.67$ ) At interim, the patient achieved complete remission. (Courtesy of Ref. (59)).

Figure 4. Simulated comparison of whole-tumor histogram analysis (top row; the blue line is the pretreatment tumor data and the red line is the post treatment tumor data) versus the corresponding voxel-based analysis using a joint density histogram (bottom row). Histograms from tumors with (A) no major change, (B) significant uniform shift to higher ADC values with a 34\% net mean change, and (C) heterogeneous ADC changes (increased and decreased ADC values) resulting in no net detectable histogram shift. Parametric response maps from the corresponding histograms above where (D) the confidence interval for detection of change was set to $95 \%$, thus no significant change in red voxels (increased values) or blue voxels (decreased values) was detected. (E) An increase in the number of red voxels was detected at $29 \%$ of the total tumor yoxels. (F) Both an increase and a decrease in tumor voxels of approximately $15 \%$ 
were detected, whereas no major shift was detected using a histogram analysis of the same data (C). (Courtesy of Ref. (85)).

Figure 5. Functional Diffusion Mapping (fDM) applied to clinical data acquired from HNSCC patients diagnosed as (A) pCR (pathological complete response) and (B) PR (partial response). Results from the fDM analysis are presented as color-coded maps superimposed on contrastenhanced T1-weighted images and scatter plots with axes pretreatment ADC (x-axis) and posttreatment ADC (y-axis). Color-coding is as followed: red indicates increased ADC values, blue indicates decreased ADC values and green indicates unchanged ADC values. (Courtesy of Ref. (65)).

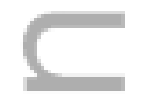

Figure 6. Number of annual publications on the application of DW-MRI for therapeutic response assessment. Yearly evaluation showed a growing increase in the number of studies demonstrating the efficacy of DW-MRI for cancer response to treatment. Search was performed on Pubmed using the following criteria [((diffusion OR ADC OR "apparent diffusion coefficient") AND MRI AND response) NOT (stroke OR review)]. Individual references were manually evaluated.

This article is protected by copyright. All rights reserved. 


\section{REFERENCES}

1. Gehan EA, Schneiderman MA. Historical and methodological developments in clinical trials at the National Cancer Institute. Stat Med 1990;9(8):871-80; discussion 903-6.

2. Eisenhauer EA, Therasse P, Bogaerts J, Schwartz LH, Sargent D, Ford R, et al. New response evaluation criteria in solid tumours: revised RECIST guideline (version 1.1). Eur J Cancer 2009;45(2):228-47.

3. - Wen PY, Macdonald DR, Reardon DA, Cloughesy TF, Sorensen AG, Galanis E, et al. Updated response assessment criteria for high-grade gliomas: response assessment in neuro-oncology working group. J Clin Oncol 2010;28(11):1963-72.

4. World Health Organization. WHO handbook for reporting results of cancer treatment. Geneva: The Organization; 1979.45 p. p.

5. Jaffe CC. Measures of response: RECIST, WHO, and new alternatives. J Clin Oncol 2006;24(20):3245-51.

6. Choi H, Charnsangavej C, de Castro Faria S, Tamm EP, Benjamin RS, Johnson MM, et al. CT evaluation of the response of gastrointestinal stromal tumors after imatinib mesylate treatment: a quantitative analysis correlated with FDG PET findings. AJR Am J Roentgenol 2004;183(6):1619-28.

7. Strumberg D, Richly H, Hilger RA, Schleucher N, Korfee S, Tewes M, et al. Phase I clinical and pharmacokinetic study of the Novel Raf kinase and vascular endothelial growth factor receptor inhibitor BAY 43-9006 in patients with advanced refractory solid tumors. J Clin Oncol 2005;23(5):965-72.

8. Barrington SF, Mikhaeel NG, Kostakoglu L, Meignan M, Hutchings M, Mueller SP, et al. Role of imaging in the staging and response assessment of lymphoma: consensus of the International Conference on Malignant Lymphomas Imaging Working Group. Journal of clinical oncology : official journal of the American Society of Clinical Oncology 2014;32(27):3048-58.

9. Cheson BD, Fisher RI, Barrington SF, Cavalli F, Schwartz LH, Zucca E, et al. Recommendations for initial evaluation, staging, and response assessment of Hodgkin and non-Hodgkin lymphoma: the Lugano classification. Journal of clinical oncology : official journal of the American Society of Clinical Oncology 2014;32(27):3059-68.

10. Stejskal E, Tanner J. Spin Diffusion Measurements: Spin Echoes in the Presence of a Time-Dependent Field Gradient. J Chem Phys 1965;42(1):288-92.

11. Thomsen C, Henriksen 0, Ring P. In vivo measurement of water self diffusion in the human brain by magnetic resonance imaging. Acta Radiol 1987;28(3):353-61.

12. Merboldt KD, Bruhn H, Frahm J, Gyngell ML, Hanicke W, Deimling M. MRI of "diffusion" in the human brain: new results using a modified CE-FAST sequence. Magn Reson Med 1989;9(3):423-9. 
13. Le Bihan D, Breton E, Lallemand D, Aubin ML, Vignaud J, Laval-Jeantet M. Separation of diffusion and perfusion in intravoxel incoherent motion MR imaging. Radiology 1988;168(2):497-505.

14. Le Bihan D. Molecular diffusion nuclear magnetic resonance imaging. Magn Reson Q 1991;7(1):1-30.

15. Bammer R. Basic principles of diffusion-weighted imaging. Eur J Radiol 2003;45(3):169-84.

16. Padhani AR, Liu G, Koh DM, Chenevert TL, Thoeny HC, Takahara T, et al. Diffusionweighted magnetic resonance imaging as a cancer biomarker: consensus and - recommendations. Neoplasia 2009;11(2):102-25.

17. Edelman RR, Wielopolski P, Schmitt F. Echo-planar MR imaging. Radiology 1994;192(3):600-12.

18. Hamstra DA, Rehemtulla A, Ross BD. Diffusion magnetic resonance imaging: a biomarker for treatment response in oncology. J Clin Oncol 2007;25(26):4104-9.

19. Lyng H, Haraldseth O, Rofstad EK. Measurement of cell density and necrotic fraction in human melanoma xenografts by diffusion weighted magnetic resonance imaging. Magn Reson Med 2000;43(6):828-36.

20. Guo AC, Cummings TJ, Dash RC, Provenzale JM. Lymphomas and high-grade astrocytomas: comparison of water diffusibility and histologic characteristics. Radiology 2002;224(1):177-83.

21. Chenevert TL, Stegman LD, Taylor JM, Robertson PL, Greenberg HS, Rehemtulla A, et al. Diffusion magnetic resonance imaging: an early surrogate marker of therapeutic efficacy in brain tumors. J Natl Cancer Inst 2000;92(24):2029-36.

22. Chenevert TL, McKeever PE, Ross BD. Monitoring early response of experimental brain tumors to therapy using diffusion magnetic resonance imaging. Clin Cancer Res 1997;3(9):1457-66.

23. Le Bihan D. The 'wet mind': water and functional neuroimaging. Phys Med Biol 2007;52(7):R57-90.

24. Chenevert TL, Sundgren PC, Ross BD. Diffusion imaging: insight to cell status and cytoarchitecture. Neuroimaging Clin N Am 2006;16(4):619-32, viii-ix.

25. Ross BD, Moffat BA, Lawrence TS, Mukherji SK, Gebarski SS, Quint DJ, et al. Evaluation of cancer therapy using diffusion magnetic resonance imaging. Mol Cancer Ther 2003;2(6):581-7.

26. Huang CF, Chou HH, Tu HT, Yang MS, Lee JK, Lin LY. Diffusion magnetic resonance imaging as an evaluation of the response of brain metastases treated by stereotactic radiosurgery. Surgical neurology 2008;69(1):62-8; discussion 68.

27. Lee KC, Hamstra DA, Bhojani MS, Khan AP, Ross BD, Rehemtulla A. Noninvasive molecular imaging sheds light on the synergy between 5-fluorouracil and TRAIL/Apo2L for cancer therapy. Clin Cancer Res 2007;13(6):1839-46. 
28. Lee KC, Hall DE, Hoff BA, Moffat BA, Sharma S, Chenevert TL, et al. Dynamic imaging of emerging resistance during cancer therapy. Cancer Res 2006;66(9):4687-92.

29. Lee KC, Bradley DA, Hussain M, Meyer CR, Chenevert TL, Jacobson JA, et al. A feasibility study evaluating the functional diffusion map as a predictive imaging biomarker for detection of treatment response in a patient with metastatic prostate cancer to the bone. Neoplasia 2007;9(12):1003-11.

30. Hamstra DA, Lee KC, Tychewicz JM, Schepkin VD, Moffat BA, Chen M, et al. The use of $19 \mathrm{~F}$ spectroscopy and diffusion-weighted MRI to evaluate differences in genedependent enzyme prodrug therapies. Mol Ther 2004;10(5):916-28.

31. = Bufi E, Belli P, Di Matteo M, Terribile D, Franceschini G, Nardone L, et al. Effect of breast cancer phenotype on diagnostic performance of MRI in the prediction to response to neoadjuvant treatment. Eur J Radiol 2014;83(9):1631-8.

32. Chinnaiyan AM, Prasad U, Shankar S, Hamstra DA, Shanaiah M, Chenevert TL, et al. Combined effect of tumor necrosis factor-related apoptosis-inducing ligand and ionizing radiation in breast cancer therapy. Proc Natl Acad Sci U S A 2000;97(4):1754-9.

33. Gaeta M, Benedetto C, Minutoli F, D'Angelo T, Amato E, Mazziotti S, et al. Use of diffusion-weighted, intravoxel incoherent motion, and dynamic contrast-enhanced MR imaging in the assessment of response to radiotherapy of lytic bone metastases from breast cancer. Academic radiology 2014;21(10):1286-93.

34. Liu L, Wu N, Ouyang H, Dai JR, Wang WH. Diffusion-weighted MRI in early assessment of tumour response to radiotherapy in high-risk prostate cancer. $\mathrm{Br} \mathrm{J}$ Radiol 2014;87(1043):20140359.

35. Pickles MD, Gibbs P, Lowry M, Turnbull LW. Diffusion changes precede size reduction in neoadjuvant treatment of breast cancer. Magn Reson Imaging 2006;24(7):843-7.

36. Sharma U, Danishad KK, Seenu V, Jagannathan NR. Longitudinal study of the assessment by MRI and diffusion-weighted imaging of tumor response in patients with locally advanced breast cancer undergoing neoadjuvant chemotherapy. NMR in biomedicine 2009;22(1):104-13.

37. Theilmann RJ, Borders R, Trouard TP, Xia G, Outwater E, Ranger-Moore J, et al. Changes in water mobility measured by diffusion MRI predict response of metastatic breast cancer to chemotherapy. Neoplasia 2004;6(6):831-7.

38. Yankeelov TE, Lepage M, Chakravarthy A, Broome EE, Niermann KJ, Kelley MC, et al. - Integration of quantitative DCE-MRI and ADC mapping to monitor treatment response in human breast cancer: initial results. Magnetic resonance imaging 2007;25(1):1-13.

39. Bonekamp S, Jolepalem P, Lazo M, Gulsun MA, Kiraly AP, Kamel IR. Hepatocellular carcinoma: response to TACE assessed with semiautomated volumetric and 
functional analysis of diffusion-weighted and contrast-enhanced MR imaging data. Radiology 2011;260(3):752-61.

40. Corona-Villalobos CP, Halappa VG, Geschwind JF, Bonekamp S, Reyes D, Cosgrove D, et al. Volumetric assessment of tumour response using functional MR imaging in patients with hepatocellular carcinoma treated with a combination of doxorubicineluting beads and sorafenib. Eur Radiol 2014.

41. Deng J, Miller FH, Rhee TK, Sato KT, Mulcahy MF, Kulik LM, et al. Diffusion-weighted MR imaging for determination of hepatocellular carcinoma response to yttrium-90 radioembolization. J Vasc Interv Radiol 2006;17(7):1195-200.

42. = Kamel IR, Bluemke DA, Eng J, Liapi E, Messersmith W, Reyes DK, et al. The role of functional MR imaging in the assessment of tumor response after chemoembolization in patients with hepatocellular carcinoma. Journal of vascular and interventional radiology : JVIR 2006;17(3):505-12.

43. Kamel IR, Liapi E, Reyes DK, Zahurak M, Bluemke DA, Geschwind JF. Unresectable hepatocellular carcinoma: serial early vascular and cellular changes after transarterial chemoembolization as detected with MR imaging. Radiology 2009;250(2):466-73.

44. Kamel IR, Reyes DK, Liapi E, Bluemke DA, Geschwind JF. Functional MR imaging assessment of tumor response after 90Y microsphere treatment in patients with unresectable hepatocellular carcinoma. Journal of vascular and interventional radiology : JVIR 2007;18(1 Pt 1):49-56.

45. Mannelli L, Kim S, Hajdu CH, Babb JS, Taouli B. Serial diffusion-weighted MRI in patients with hepatocellular carcinoma: Prediction and assessment of response to transarterial chemoembolization. Preliminary experience. Eur J Radiol 2013;82(4):577-82.

46. Rhee TK, Naik NK, Deng J, Atassi B, Mulcahy MF, Kulik LM, et al. Tumor response after yttrium-90 radioembolization for hepatocellular carcinoma: comparison of diffusion-weighted functional MR imaging with anatomic MR imaging. Journal of vascular and interventional radiology : JVIR 2008;19(8):1180-6.

47. Yu JS, Kim JH, Chung JJ, Kim KW. Added value of diffusion-weighted imaging in the MRI assessment of perilesional tumor recurrence after chemoembolization of hepatocellular carcinomas. J Magn Reson Imaging 2009;30(1):153-60.

48. Zelhof B, Pickles M, Liney G, Gibbs P, Rodrigues G, Kraus S, et al. Correlation of diffusion-weighted magnetic resonance data with cellularity in prostate cancer. BJU Int 2008.

49. Barbaro B, Vitale R, Valentini V, Illuminati S, Vecchio FM, Rizzo G, et al. Diffusionweighted magnetic resonance imaging in monitoring rectal cancer response to neoadjuvant chemoradiotherapy. International journal of radiation oncology, biology, physics 2012;83(2):594-9. 
50. Birlik B, Obuz F, Elibol FD, Celik AO, Sokmen S, Terzi C, et al. Diffusion-Weighted Mri and Mr- volumetry - in the Evaluation of Tumor Response After Preoperative Chemoradiotherapy in Patients with Locally Advanced Rectal Cancer. Magn Reson Imaging 2014.

51. Carbone SF, Pirtoli L, Ricci V, Carfagno T, Tini P, Lazzi S, et al. Diffusion-weighted MR volumetry for assessing the response of rectal cancer to combined radiation therapy with chemotherapy. Radiology 2012;263(1):311.

52. Carbone SF, Pirtoli L, Ricci V, Venezia D, Carfagno T, Lazzi S, et al. Assessment of response to chemoradiation therapy in rectal cancer using MR volumetry based on

= diffusion-weighted data sets: a preliminary report. La Radiologia medica 2012;117(7):1112-24.

53. Genovesi D, Filippone A, Ausili Cefaro G, Trignani M, Vinciguerra A, Augurio A, et al. Diffusion-weighted magnetic resonance for prediction of response after neoadjuvant chemoradiation therapy for locally advanced rectal cancer: preliminary results of a monoinstitutional prospective study. European journal of surgical oncology : the journal of the European Society of Surgical Oncology and the British Association of Surgical Oncology 2013;39(10):1071-8.

54. Hein PA, Kremser C, Judmaier W, Griebel J, Pfeiffer KP, Kreczy A, et al. Diffusionweighted magnetic resonance imaging for monitoring diffusion changes in rectal carcinoma during combined, preoperative chemoradiation: preliminary results of a prospective study. European journal of radiology 2003;45(3):214-22.

55. Ippolito D, Monguzzi L, Guerra L, Deponti E, Gardani G, Messa C, et al. Response to neoadjuvant therapy in locally advanced rectal cancer: assessment with diffusionweighted MR imaging and 18FDG PET/CT. Abdominal imaging 2012;37(6):1032-40.

56. Kim SH, Lee JM, Hong SH, Kim GH, Lee JY, Han JK, et al. Locally advanced rectal cancer: added value of diffusion-weighted MR imaging in the evaluation of tumor response to neoadjuvant chemo- and radiation therapy. Radiology 2009;253(1):116-25.

57. Kim SH, Ryu KH, Yoon JH, Lee Y, Paik JH, Kim SJ, et al. Apparent diffusion coefficient for lymph node characterization after chemoradiation therapy for locally advanced rectal cancer. Acta Radiol 2014.

58. De Paepe K, Bevernage C, De Keyzer F, Wolter P, Gheysens O, Janssens A, et al. Whole-body diffusion-weighted magnetic resonance imaging at 3 Tesla for early assessment of treatment response in non-Hodgkin lymphoma: a pilot study. Cancer imaging : the official publication of the International Cancer Imaging Society 2013;13:53-62.

59. Horger M, Claussen C, Kramer U, Fenchel M, Lichy M, Kaufmann S. Very early indicators of response to systemic therapy in lymphoma patients based on alterations in water diffusivity--a preliminary experience in 20 patients undergoing whole-body diffusion-weighted imaging. Eur J Radiol 2014;83(9):1655-64. 
60. Montoro J, Laszlo D, Zing NP, Petralia G, Conte G, Colandrea M, et al. Comparison of whole-body diffusion-weighted magnetic resonance and FDG-PET/CT in the assessment of Hodgkin's lymphoma for staging and treatment response. Ecancermedicalscience 2014;8:429.

61. Prat MC, Surapaneni K, Chalian H, DeLaPaz RL, Kazim M. Ocular adnexal lymphoma: monitoring response to therapy with diffusion-weighted imaging. Ophthalmic plastic and reconstructive surgery 2013;29(6):424-7.

62. Siegel MJ, Jokerst CE, Rajderkar D, Hildebolt CF, Goyal S, Dehdashti F, et al. Diffusionweighted MRI for staging and evaluation of response in diffuse large B-cell lymphoma: a pilot study. NMR Biomed 2014;27(6):681-91.

63. Tsuji K, Kishi S, Tsuchida T, Yamauchi T, Ikegaya S, Urasaki Y, et al. Evaluation of staging and early response to chemotherapy with whole-body diffusion-weighted MRI in malignant lymphoma patients: A comparison with FDG-PET/CT. J Magn Reson Imaging 2014.

64. Ding Y, Fuller C, Mohamed A, Wang J, Hazle J. TU-F-CAMPUS-I-01: Head and Neck Squamous Cell Carcinoma: Short-Term Repeatability of Apparent Diffusion Coefficient and Intravoxel Incoherent Motion Parameters at 3.0T. Med Phys 2015;42(6):3646.

65. Galban CJ, Mukherji SK, Chenevert TL, Meyer CR, Hamstra DA, Bland PH, et al. A feasibility study of parametric response map analysis of diffusion-weighted magnetic resonance imaging scans of head and neck cancer patients for providing early detection of therapeutic efficacy. Translational oncology 2009;2(3):184-90.

66. Blackledge MD, Collins DJ, Tunariu N, Orton MR, Padhani AR, Leach MO, et al. Assessment of treatment response by total tumor volume and global apparent diffusion coefficient using diffusion-weighted MRI in patients with metastatic bone disease: a feasibility study. PloS one 2014;9(4):e91779.

67. Byun WM, Shin SO, Chang Y, Lee SJ, Finsterbusch J, Frahm J. Diffusion-weighted MR imaging of metastatic disease of the spine: assessment of response to therapy. AJNR Am J Neuroradiol 2002;23(6):906-12.

68. Cui Y, Zhang XP, Sun YS, Tang L, Shen L. Apparent diffusion coefficient: potential imaging biomarker for prediction and early detection of response to chemotherapy in hepatic metastases. Radiology 2008;248(3):894-900.

69. Kukuk GM, Murtz P, Traber F, Meyer C, Ullrich J, Gieseke J, et al. Diffusion-weighted imaging with acquisition of three $b$-values for response evaluation of -neuroendocrine liver metastases undergoing selective internal radiotherapy. Eur Radiol 2014;24(2):267-76.

70. Marugami N, Tanaka T, Kitano S, Hirohashi S, Nishiofuku H, Takahashi A, et al. Early detection of therapeutic response to hepatic arterial infusion chemotherapy of liver metastases from colorectal cancer using diffusion-weighted MR imaging. Cardiovasc Intervent Radiol 2009;32(4):638-46. 
71. Mungai F, Pasquinelli F, Mazzoni LN, Virgili G, Ragozzino A, Quaia E, et al. Diffusionweighted magnetic resonance imaging in the prediction and assessment of chemotherapy outcome in liver metastases. La Radiologia medica 2014;119(8):62533.

72. Schmidt S, Dunet V, Koehli M, Montemurro M, Meuli R, Prior JO. Diffusion-weighted magnetic resonance imaging in metastatic gastrointestinal stromal tumor (GIST): a pilot study on the assessment of treatment response in comparison with 18F-FDG PET/CT. Acta Radiol 2013;54(8):837-42.

73. Li X, Abramson RG, Arlinghaus LR, Kang H, Chakravarthy AB, Abramson VG, et al. - Multiparametric Magnetic Resonance Imaging for Predicting Pathological Response After the First Cycle of Neoadjuvant Chemotherapy in Breast Cancer. Invest Radiol 2014.

74. Uhl M, Saueressig U, van Buiren M, Kontny U, Niemeyer C, Kohler G, et al. Osteosarcoma: preliminary results of in vivo assessment of tumor necrosis after chemotherapy with diffusion- and perfusion-weighted magnetic resonance imaging. Invest Radiol 2006;41(8):618-23.

75. Hein PA, Eskey CJ, Dunn JF, Hug EB. Diffusion-weighted imaging in the follow-up of treated high-grade gliomas: tumor recurrence versus radiation injury. AJNR Am J Neuroradiol 2004;25(2):201-9.

76. Reischauer C, Froehlich JM, Koh DM, Graf N, Padevit C, John H, et al. Bone metastases from prostate cancer: assessing treatment response by using diffusion-weighted imaging and functional diffusion maps--initial observations. Radiology 2010;257(2):523-31.

77. Takahara T, Imai Y, Yamashita T, Yasuda S, Nasu S, Van Cauteren M. Diffusion weighted whole body imaging with background body signal suppression (DWIBS): technical improvement using free breathing, STIR and high resolution 3D display. Radiation medicine 2004;22(4):275-82.

78. Kwee TC, Takahara T, Ochiai R, Nievelstein RA, Luijten PR. Diffusion-weighted whole-body imaging with background body signal suppression (DWIBS): features and potential applications in oncology. Eur Radiol 2008;18(9):1937-52.

79. Dzik-Jurasz A, Domenig C, George M, Wolber J, Padhani A, Brown G, et al. Diffusion MRI for prediction of response of rectal cancer to chemoradiation. Lancet 2002;360(9329):307-8.

80. Kremser C, Judmaier W, Hein P, Griebel J, Lukas P, de Vries A. Preliminary results on -the influence of chemoradiation on apparent diffusion coefficients of primary rectal carcinoma measured by magnetic resonance imaging. Strahlenther Onkol 2003;179(9):641-9.

81. Jacobs MA, Herskovits EH, Kim HS. Uterine fibroids: diffusion-weighted MR imaging for monitoring therapy with focused ultrasound surgery--preliminary study. Radiology 2005;236(1):196-203. 
82. Aliu SO, Wilmes LJ, Moasser MM, Hann BC, Li KL, Wang D, et al. MRI methods for evaluating the effects of tyrosine kinase inhibitor administration used to enhance chemotherapy efficiency in a breast tumor xenograft model. J Magn Reson Imaging 2009;29(5):1071-9.

83. Just N. Improving tumour heterogeneity MRI assessment with histograms. Br J Cancer 2014;111(12):2205-13.

84. Woo S, Cho JY, Kim SY, Kim SH. Histogram analysis of apparent diffusion coefficient map of diffusion-weighted MRI in endometrial cancer: a preliminary correlation study with histological grade. Acta Radiol 2014;55(10):1270-7.

85. = Boes JL, Hoff BA, Hylton N, Pickles MD, Turnbull LW, Schott AF, et al. Image registration for quantitative parametric response mapping of cancer treatment response. Transl Oncol 2014;7(1):101-10.

86. Lemasson B, Chenevert TL, Lawrence TS, Tsien C, Sundgren PC, Meyer CR, et al. Impact of perfusion map analysis on early survival prediction accuracy in glioma patients. Transl Oncol 2013;6(6):766-74.

87. Moffat BA, Chenevert TL, Lawrence TS, Meyer CR, Johnson TD, Dong Q, et al. Functional diffusion map: a noninvasive MRI biomarker for early stratification of clinical brain tumor response. Proceedings of the National Academy of Sciences of the United States of America 2005;102(15):5524-9.

88. Li X, Dawant BM, Welch EB, Chakravarthy AB, Freehardt D, Mayer I, et al. A nonrigid registration algorithm for longitudinal breast MR images and the analysis of breast tumor response. Magn Reson Imaging 2009;27(9):1258-70.

89. Li X, Dawant BM, Welch EB, Chakravarthy AB, Xu L, Mayer I, et al. Validation of an algorithm for the nonrigid registration of longitudinal breast MR images using realistic phantoms. Med Phys 2010;37(6):2541-52.

90. Ellingson BM, Cloughesy TF, Lai A, Nghiemphu PL, Liau LM, Pope WB. Quantitative probabilistic functional diffusion mapping in newly diagnosed glioblastoma treated with radiochemotherapy. Neuro-oncology 2013;15(3):382-90.

91. Ellingson BM, Cloughesy TF, Zaw T, Lai A, Nghiemphu PL, Harris R, et al. Functional diffusion maps (fDMs) evaluated before and after radiochemotherapy predict progression-free and overall survival in newly diagnosed glioblastoma. Neurooncology 2012;14(3):333-43.

92. Hamstra DA, Chenevert TL, Moffat BA, Johnson TD, Meyer CR, Mukherji SK, et al. Evaluation of the functional diffusion map as an early biomarker of time-to-progression and overall survival in high-grade glioma. Proc Natl Acad Sci U S A 2005;102(46):16759-64.

93. Hamstra DA, Galban CJ, Meyer CR, Johnson TD, Sundgren PC, Tsien C, et al. Functional diffusion map as an early imaging biomarker for high-grade glioma: correlation with conventional radiologic response and overall survival. J Clin Oncol 2008;26(20):3387-94. 
94. Padhani AR, Liu G, Mu-Koh D, Chenevert TL, Thoeny HC, Takahara T, et al. Diffusionweighted magnetic resonance imaging as a cancer biomarker: consensus and recommendations. Neoplasia 2009;11(2):102-25.

95. Delakis I, Moore EM, Leach MO, De Wilde JP. Developing a quality control protocol for diffusion imaging on a clinical MRI system. Phys Med Biol 2004;49(8):1409-22.

96. Laubach HJ, Jakob PM, Loevblad KO, Baird AE, Bovo MP, Edelman RR, et al. A phantom for diffusion-weighted imaging of acute stroke. J Magn Reson Imaging 1998;8(6):1349-54.

97. Tofts PS, Lloyd D, Clark CA, Barker GJ, Parker GJ, McConville P, et al. Test liquids for = quantitative MRI measurements of self-diffusion coefficient in vivo. Magn Reson Med 2000;43(3):368-74.

98. Chenevert TL, Galban CJ, Ivancevic MK, Rohrer SE, Londy FJ, Kwee TC, et al. Diffusion coefficient measurement using a temperature-controlled fluid for quality control in multicenter studies. J Magn Reson Imaging 2011;34(4):983-7.

99. Simpson JH, Carr HY. Diffusion and nuclear spin relaxation in water. Phys Rev 1958;111:1201-2.

100. Belli G, Busoni S, Ciccarone A, Coniglio A, Esposito M, Giannelli M, et al. Quality assurance multicenter comparison of different MR scanners for quantitative diffusion-weighted imaging. J Magn Reson Imaging 2015.

101. Malyarenko D, Galban CJ, Londy FJ, Meyer CR, Johnson TD, Rehemtulla A, et al. Multisystem repeatability and reproducibility of apparent diffusion coefficient measurement using an ice-water phantom. J Magn Reson Imaging 2013;37(5):123846.

102. Kakite S, Dyvorne H, Besa C, Cooper N, Facciuto M, Donnerhack C, et al. Hepatocellular carcinoma: short-term reproducibility of apparent diffusion coefficient and intravoxel incoherent motion parameters at 3.0T. J Magn Reson Imaging 2015;41(1):149-56.

103. Bernardin L, Douglas NH, Collins DJ, Giles SL, O'Flynn EA, Orton M, et al. Diffusionweighted magnetic resonance imaging for assessment of lung lesions: repeatability of the apparent diffusion coefficient measurement. Eur Radiol 2014;24(2):502-11.

104. Intven M, Reerink O, Philippens ME. Repeatability of diffusion-weighted imaging in rectal cancer. J Magn Reson Imaging 2014;40(1):146-50.

105. Galban CJ, Ma B, Malyarenko D, Pickles MD, Heist K, Henry NL, et al. Multi-site clinical evaluation of DW-MRI as a treatment response metric for breast cancer -patients undergoing neoadjuvant chemotherapy. PloS one 2015;10(3):e0122151.

106. Heo S, Cho HJ, Jeon IS. A case of posterior reversible encephalopathy syndrome in a child with myelodysplastic syndrome following allogenic bone marrow transplantation. Pediatric hematology and oncology 2010;27(1):59-64. 
107. Huang RY, Neagu MR, Reardon DA, Wen PY. Pitfalls in the neuroimaging of glioblastoma in the era of antiangiogenic and immuno/targeted therapy - detecting illusive disease, defining response. Frontiers in neurology 2015;6:33.

108. Rygh CB, Wang J, Thuen M, Gras Navarro A, Huuse EM, Thorsen F, et al. Dynamic contrast enhanced MRI detects early response to adoptive NK cellular immunotherapy targeting the NG2 proteoglycan in a rat model of glioblastoma. PloS one 2014;9(9):e108414.

109. McDonald K, Sebire NJ, Anderson J, Olsen OE. Patterns of shift in ADC distributions in abdominal tumours during chemotherapy-feasibility study. Pediatric radiology - 2011;41(1):99-106.

110. Wai Y, Chu J, Wang C, Lin Y, Lin G, Wan Y, et al. An integrated diffusion map for the analysis of diffusion properties: a feasibility study in patients with acoustic neuroma. Academic radiology 2009;16(4):428-34.

111. Nakayama T, Yoshida S, Fujii Y, Koga F, Saito K, Masuda H, et al. [Use of diffusionweighted MRI in monitoring response of lymph node metastatic bladder cancer treated with chemotherary]. Nihon Hinyokika Gakkai zasshi The japanese journal of urology 2008;99(7):737-41.

112. Yoshida S, Koga F, Kawakami S, Ishii C, Tanaka H, Numao N, et al. Initial experience of diffusion-weighted magnetic resonance imaging to assess therapeutic response to induction chemoradiotherapy against muscle-invasive bladder cancer. Urology 2010;75(2):387-91.

113. Ballon D, Watts R, Dyke JP, Lis E, Morris MJ, Scher HI, et al. Imaging therapeutic response in human bone marrow using rapid whole-body MRI. Magnetic resonance in medicine 2004;52(6):1234-8.

114. Armitage PA, Schwindack C, Bastin ME, Whittle IR. Quantitative assessment of intracranial tumor response to dexamethasone using diffusion, perfusion and permeability magnetic resonance imaging. Magnetic resonance imaging 2007;25(3):303-10.

115. Bastin ME, Delgado M, Whittle IR, Cannon J, Wardlaw JM. The use of diffusion tensor imaging in quantifying the effect of dexamethasone on brain tumours. Neuroreport 1999;10(7):1385-91.

116. Huang CF, Chiou SY, Wu MF, Tu HT, Liu WS, Chuang JC. Apparent diffusion coefficients for evaluation of the response of brain tumors treated by Gamma Knife surgery. Journal of neurosurgery 2010;113 Suppl:97-104.

117. Mardor Y, Roth Y, Lidar Z, Jonas T, Pfeffer R, Maier SE, et al. Monitoring response to convection-enhanced taxol delivery in brain tumor patients using diffusionweighted magnetic resonance imaging. Cancer research 2001;61(13):4971-3.

118. Mardor Y, Roth Y, Ochershvilli A, Spiegelmann R, Tichler T, Daniels D, et al. Pretreatment prediction of brain tumors' response to radiation therapy using high b-value diffusion-weighted MRI. Neoplasia 2004;6(2):136-42. 
119. Mardor Y, Pfeffer R, Spiegelmann R, Roth Y, Maier SE, Nissim O, et al. Early detection of response to radiation therapy in patients with brain malignancies using conventional and high $b$-value diffusion-weighted magnetic resonance imaging. Journal of clinical oncology : official journal of the American Society of Clinical Oncology 2003;21(6):1094-100.

120. Tomura N, Narita K, Izumi J, Suzuki A, Anbai A, Otani T, et al. Diffusion changes in a tumor and peritumoral tissue after stereotactic irradiation for brain tumors: possible prediction of treatment response. Journal of computer assisted tomography 2006;30(3):496-500.

121.= Goldman M, Boxerman JL, Rogg JM, Noren G. Utility of apparent diffusion coefficient in predicting the outcome of Gamma Knife-treated brain metastases prior to changes in tumor volume: a preliminary study. Journal of neurosurgery 2006;105 Suppl:175-82.

122. Gupta A, Young RJ, Karimi S, Sood S, Zhang Z, Mo Q, et al. Isolated diffusion restriction precedes the development of enhancing tumor in a subset of patients with glioblastoma. AJNR American journal of neuroradiology 2011;32(7):1301-6.

123. Hattingen E, Jurcoane A, Bahr O, Rieger J, Magerkurth J, Anti S, et al. Bevacizumab impairs oxidative energy metabolism and shows antitumoral effects in recurrent glioblastomas: a 31P/1H MRSI and quantitative magnetic resonance imaging study. Neuro-oncology 2011;13(12):1349-63.

124. Pope WB, Lai A, Mehta R, Kim HJ, Qiao J, Young JR, et al. Apparent diffusion coefficient histogram analysis stratifies progression-free survival in newly diagnosed bevacizumab-treated glioblastoma. AJNR American journal of neuroradiology 2011;32(5):882-9.

125. Vrabec M, Van Cauter S, Himmelreich U, Van Gool SW, Sunaert S, De Vleeschouwer S, et al. MR perfusion and diffusion imaging in the follow-up of recurrent glioblastoma treated with dendritic cell immunotherapy: a pilot study. Neuroradiology 2011;53(10):721-31.

126. Yamasaki F, Kurisu K, Aoki T, Yamanaka M, Kajiwara Y, Watanabe Y, et al. Advantages of high b-value diffusion-weighted imaging to diagnose pseudoresponses in patients with recurrent glioma after bevacizumab treatment. European journal of radiology 2012;81(10):2805-10.

127. Galban CJ, Chenevert TL, Meyer CR, Tsien C, Lawrence TS, Hamstra DA, et al. Prospective analysis of parametric response map-derived MRI biomarkers: identification of early and distinct glioma response patterns not predicted by standard radiographic assessment. Clinical cancer research : an official journal of the American Association for Cancer Research 2011;17(14):4751-60.

128. Nowosielski M, Recheis W, Goebel G, Guler O, Tinkhauser G, Kostron H, et al. ADC histograms predict response to anti-angiogenic therapy in patients with recurrent high-grade glioma. Neuroradiology 2011;53(4):291-302. 
129. Prabhu SP, Ng S, Vajapeyam S, Kieran MW, Pollack IF, Geyer R, et al. DTI assessment of the brainstem white matter tracts in pediatric BSG before and after therapy: a report from the Pediatric Brain Tumor Consortium. Child's nervous system : ChNS : official journal of the International Society for Pediatric Neurosurgery 2011;27(1):11-8.

130. Ringelstein A, Turowski B, Gizewski ER, Schroeteler J, Rapp M, Saleh A, et al. [Evaluation of ADC mapping as an early predictor for tumor response to chemotherapy in recurrent glioma treated with bevacizumab/irinotecan: proof of principle]. RoFo : Fortschritte auf dem Gebiete der Rontgenstrahlen und der - Nuklearmedizin 2010;182(10):868-72.

131. Chen HJ, Panigrahy A, Dhall G, Finlay JL, Nelson MD, Jr., Bluml S. Apparent diffusion and fractional anisotropy of diffuse intrinsic brain stem gliomas. AJNR American journal of neuroradiology 2010;31(10):1879-85.

132. Jain R, Scarpace LM, Ellika S, Torcuator R, Schultz LR, Hearshen D, et al. Imaging response criteria for recurrent gliomas treated with bevacizumab: role of diffusion weighted imaging as an imaging biomarker. Journal of neuro-oncology 2010;96(3):423-31.

133. Seshadri M, Ciesielski MJ. MRI-based characterization of vascular disruption by 5,6dimethylxanthenone-acetic acid in gliomas. Journal of cerebral blood flow and metabolism : official journal of the International Society of Cerebral Blood Flow and Metabolism 2009;29(8):1373-82.

134. Jager HR, Waldman AD, Benton C, Fox N, Rees J. Differential chemosensitivity of tumor components in a malignant oligodendroglioma: assessment with diffusionweighted, perfusion-weighted, and serial volumetric MR imaging. AJNR American journal of neuroradiology 2005;26(2):274-8.

135. Lidar Z, Mardor Y, Jonas T, Pfeffer R, Faibel M, Nass D, et al. Convection-enhanced delivery of paclitaxel for the treatment of recurrent malignant glioma: a phase I/II clinical study. Journal of neurosurgery 2004;100(3):472-9.

136. Lin YC, Wang CC, Wai YY, Wan YL, Ng SH, Chen YL, et al. Significant temporal evolution of diffusion anisotropy for evaluating early response to radiosurgery in patients with vestibular schwannoma: findings from functional diffusion maps. AJNR American journal of neuroradiology 2010;31(2):269-74.

137. Schubert MI, Wilke M, Muller-Weihrich S, Auer DP. Diffusion-weighted magnetic resonance imaging of treatment-associated changes in recurrent and residual medulloblastoma: preliminary observations in three children. Acta radiologica 2006;47(10):1100-4.

138. Sinha S, Bastin ME, Whittle IR. Rapid clinical deterioration in a patient with multifocal glioma despite corticosteroid therapy: a quantitative MRI study. British journal of neurosurgery 2003;17(6):537-40; discussion 40 . 
139. Arlinghaus LR, Li X, Rahman AR, Welch EB, Xu L, Gore JC, et al. On the relationship between the apparent diffusion coefficient and extravascular extracellular volume fraction in human breast cancer. Magnetic resonance imaging 2011;29(5):630-8.

140. Belli P, Costantini M, Ierardi C, Bufi E, Amato D, Mule A, et al. Diffusion-weighted imaging in evaluating the response to neoadjuvant breast cancer treatment. The breast journal 2011;17(6):610-9.

141. Fangberget A, Nilsen LB, Hole KH, Holmen MM, Engebraaten O, Naume B, et al. Neoadjuvant chemotherapy in breast cancer-response evaluation and prediction of response to treatment using dynamic contrast-enhanced and diffusion-weighted MR - imaging. European radiology 2011;21(6):1188-99.

142. Jensen LR, Garzon B, Heldahl MG, Bathen TF, Lundgren S, Gribbestad IS. Diffusionweighted and dynamic contrast-enhanced MRI in evaluation of early treatment effects during neoadjuvant chemotherapy in breast cancer patients. Journal of magnetic resonance imaging : JMRI 2011;34(5):1099-109.

143. Jinming X, Qi Z, Xiaoming Z, Jianming T. Primary non-Hodgkin's lymphoma of the breast: mammography, ultrasound, MRI and pathologic findings. Future oncology 2012;8(1):105-9.

144. Kawamura M, Satake H, Ishigaki S, Nishio A, Sawaki M, Naganawa S. Early prediction of response to neoadjuvant chemotherapy for locally advanced breast cancer using MRI. Nagoya journal of medical science 2011;73(3-4):147-56.

145. Li XR, Cheng LQ, Liu M, Zhang YJ, Wang JD, Zhang AL, et al. DW-MRI ADC values can predict treatment response in patients with locally advanced breast cancer undergoing neoadjuvant chemotherapy. Medical oncology 2012;29(2):425-31.

146. Park SH, Moon WK, Cho N, Chang JM, Im SA, Park IA, et al. Comparison of diffusionweighted MR imaging and FDG PET/CT to predict pathological complete response to neoadjuvant chemotherapy in patients with breast cancer. European radiology 2012;22(1):18-25.

147. Wang XH, Peng WJ, Tan HN, Xin C, Gu YJ, Tang F, et al. [Value of diffusion weighted imaging (DWI) in evaluating early response to neoadjuvant chemotherapy in locally advanced breast cancer]. Zhonghua zhong liu za zhi [Chinese journal of oncology] 2010;32(5):377-81.

148. Buijs M, Kamel IR, Vossen JA, Georgiades CS, Hong K, Geschwind JF. Assessment of metastatic breast cancer response to chemoembolization with contrast agent enhanced and diffusion-weighted MR imaging. Journal of vascular and interventional radiology : JVIR 2007;18(8):957-63.

149. Ma B, Meyer CR, Pickles MD, Chenevert TL, Bland PH, Galban CJ, et al. Voxel-by-voxel functional diffusion mapping for early evaluation of breast cancer treatment. Information processing in medical imaging : proceedings of the conference 2009;21:276-87. 
150. Nilsen L, Fangberget A, Geier O, Olsen DR, Seierstad T. Diffusion-weighted magnetic resonance imaging for pretreatment prediction and monitoring of treatment response of patients with locally advanced breast cancer undergoing neoadjuvant chemotherapy. Acta oncologica 2010;49(3):354-60.

151. Tozaki M, Oyama Y, Fukuma E. Preliminary study of early response to neoadjuvant chemotherapy after the first cycle in breast cancer: comparison of $1 \mathrm{H}$ magnetic resonance spectroscopy with diffusion magnetic resonance imaging. Japanese journal of radiology 2010;28(2):101-9.

152. Manton DJ, Chaturvedi A, Hubbard A, Lind MJ, Lowry M, Maraveyas A, et al. = Neoadjuvant chemotherapy in breast cancer: early response prediction with quantitative MR imaging and spectroscopy. British journal of cancer 2006;94(3):427-35.

153. Harry VN, Semple SI, Gilbert FJ, Parkin DE. Diffusion-weighted magnetic resonance imaging in the early detection of response to chemoradiation in cervical cancer. Gynecologic oncology 2008;111(2):213-20.

154. Levy A, Caramella C, Chargari C, Medjhoul A, Rey A, Zareski E, et al. Accuracy of diffusion-weighted echo-planar MR imaging and ADC mapping in the evaluation of residual cervical carcinoma after radiation therapy. Gynecologic oncology 2011;123(1):110-5.

155. Liu Y, Bai R, Sun H, Liu H, Zhao X, Li Y. Diffusion-weighted imaging in predicting and monitoring the response of uterine cervical cancer to combined chemoradiation. Clinical radiology 2009;64(11):1067-74.

156. Matge G. Anterior interbody fusion with the BAK-cage in cervical spondylosis. Acta neurochirurgica 1998;140(1):1-8.

157. McVeigh PZ, Syed AM, Milosevic M, Fyles A, Haider MA. Diffusion-weighted MRI in cervical cancer. European radiology 2008;18(5):1058-64.

158. Rizzo S, Summers P, Raimondi S, Belmonte M, Maniglio M, Landoni F, et al. Diffusionweighted MR imaging in assessing cervical tumour response to nonsurgical therapy. La Radiologia medica 2011;116(5):766-80.

159. Zhang Y, Chen JY, Xie CM, Mo YX, Liu XW, Liu Y, et al. Diffusion-weighted magnetic resonance imaging for prediction of response of advanced cervical cancer to chemoradiation. Journal of computer assisted tomography 2011;35(1):102-7.

160. Zhang Y, Liang BL, Gao L, Ye RX, Shen J, Zhong JL. [Diffusion weighted imaging features of normal uterine cervix and cervical carcinoma]. Ai zheng $=$ Aizheng $=$ Chinese journal of cancer 2007;26(5):508-12.

161. Buijs M, Vossen JA, Hong K, Georgiades CS, Geschwind JF, Kamel IR. Chemoembolization of hepatic metastases from ocular melanoma: assessment of response with contrast-enhanced and diffusion-weighted MRI. AJR American journal of roentgenology 2008;191(1):285-9. 
162. Politi LS, Forghani R, Godi C, Resti AG, Ponzoni M, Bianchi S, et al. Ocular adnexal lymphoma: diffusion-weighted $\mathrm{mr}$ imaging for differential diagnosis and therapeutic monitoring. Radiology 2010;256(2):565-74.

163. Hecht EM, Do RK, Kang SK, Bennett GL, Babb JS, Clark TW. Diffusion-weighted imaging for prediction of volumetric response of leiomyomas following uterine artery embolization: a preliminary study. Journal of magnetic resonance imaging : JMRI 2011;33(3):641-6.

164. Saraiya B, Chugh R, Karantza V, Mehnert J, Moss RA, Savkina N, et al. Phase I study of gemcitabine, docetaxel and imatinib in refractory and relapsed solid tumors. - Investigational new drugs 2012;30(1):258-65.

165. Vossen JA, Kamel IR, Buijs M, Liapi E, Georgiades CS, Hong K, et al. Role of functional magnetic resonance imaging in assessing metastatic leiomyosarcoma response to chemoembolization. Journal of computer assisted tomography 2008;32(3):347-52.

166. Choi SA, Lee SS, Jung IH, Kim HA, Byun JH, Lee MG. The effect of gadoxetic acid enhancement on lesion detection and characterisation using T(2) weighted imaging and diffusion weighted imaging of the liver. The British journal of radiology 2012;85(1009):29-36.

167. Dudeck O, Zeile M, Wybranski C, Schulmeister A, Fischbach F, Pech M, et al. Early prediction of anticancer effects with diffusion-weighted MR imaging in patients with colorectal liver metastases following selective internal radiotherapy. European radiology 2010;20(11):2699-706.

168. Koh DM, Scurr E, Collins D, Kanber B, Norman A, Leach MO, et al. Predicting response of colorectal hepatic metastasis: value of pretreatment apparent diffusion coefficients. AJR American journal of roentgenology 2007;188(4):1001-8.

169. Wybranski C, Zeile M, Lowenthal D, Fischbach F, Pech M, Rohl FW, et al. Value of diffusion weighted MR imaging as an early surrogate parameter for evaluation of tumor response to high-dose-rate brachytherapy of colorectal liver metastases. Radiation oncology 2011;6(1):43.

170. Zhang Y, Zhao J, Guo D, Zhong W, Ran L. Evaluation of short-term response of high intensity focused ultrasound ablation for primary hepatic carcinoma: utility of contrast-enhanced MRI and diffusion-weighted imaging. European journal of radiology 2011;79(3):347-52.

171. Duke E, Deng J, Ibrahim SM, Lewandowski RJ, Ryu RK, Sato KT, et al. Agreement between competing imaging measures of response of hepatocellular carcinoma to yttrium-90 radioembolization. Journal of vascular and interventional radiology : JVIR 2010;21(4):515-21.

172. Kubota K, Yamanishi T, Itoh S, Murata Y, Miyatake K, Yasunami H, et al. Role of diffusion-weighted imaging in evaluating therapeutic efficacy after transcatheter arterial chemoembolization for hepatocellular carcinoma. Oncology reports 2010;24(3):727-32. 
173. Liapi E, Geschwind JF, Vossen JA, Buijs M, Georgiades CS, Bluemke DA, et al. Functional MRI evaluation of tumor response in patients with neuroendocrine hepatic metastasis treated with transcatheter arterial chemoembolization. AJR American journal of roentgenology 2008;190(1):67-73.

174. Eccles CL, Haider EA, Haider MA, Fung S, Lockwood G, Dawson LA. Change in diffusion weighted MRI during liver cancer radiotherapy: preliminary observations. Acta oncologica 2009;48(7):1034-43.

175. Schraml C, Schwenzer NF, Martirosian P, Bitzer M, Lauer U, Claussen CD, et al. Diffusion-weighted MRI of advanced hepatocellular carcinoma during sorafenib

= treatment: initial results. AJR American journal of roentgenology 2009;193(4):W301-7.

176. Yuan Z, Ye XD, Dong S, Xu LC, Xu XY, Liu SY, et al. Role of magnetic resonance diffusion-weighted imaging in evaluating response after chemoembolization of hepatocellular carcinoma. European journal of radiology 2010;75(1):e9-14.

177. Anzidei M, Napoli A, Zaccagna F, Cartocci G, Saba L, Menichini G, et al. Liver metastases from colorectal cancer treated with conventional and antiangiogenetic chemotherapy: evaluation with liver computed tomography perfusion and magnetic resonance diffusion-weighted imaging. Journal of computer assisted tomography 2011;35(6):690-6.

178. Bonekamp S, Shen J, Salibi N, Lai HC, Geschwind J, Kamel IR. Early response of hepatic malignancies to locoregional therapy-value of diffusion-weighted magnetic resonance imaging and proton magnetic resonance spectroscopy. Journal of computer assisted tomography 2011;35(2):167-73.

179. Yuan Z, Ye XD, Dong S, Xu LC, Sun ZC, Xiao XS. [Water mobility of diffusion MRI in prediction of response to chemoembolization in liver cancer]. Zhonghua zhong liu za zhi [Chinese journal of oncology] 2009;31(4):293-7.

180. Chung JC, Naik NK, Lewandowski RJ, Deng J, Mulcahy MF, Kulik LM, et al. Diffusionweighted magnetic resonance imaging to predict response of hepatocellular carcinoma to chemoembolization. World journal of gastroenterology 2010;16(25):3161-7.

181. El-Khouli RH, Geschwind JF, Bluemke DA, Kamel IR. Solitary fibrous tumor of the liver: magnetic resonance imaging evaluation and treatment with transarterial chemoembolization. Journal of computer assisted tomography 2008;32(5):769-71.

182. Chang Q, Wu N, Ouyang H, Huang Y. Diffusion-weighted magnetic resonance imaging of lung cancer at 3.0 T: a preliminary study on monitoring diffusion changes during chemoradiation therapy. Clinical imaging 2012;36(2):98-103.

183. Ohno Y, Koyama H, Yoshikawa T, Matsumoto K, Aoyama N, Onishi Y, et al. Diffusionweighted MRI versus 18F-FDG PET/CT: performance as predictors of tumor treatment response and patient survival in patients with non-small cell lung cancer 
receiving chemoradiotherapy. AJR American journal of roentgenology 2012;198(1):75-82.

184. Okuma T, Matsuoka T, Yamamoto A, Hamamoto S, Nakamura K, Inoue Y. Assessment of early treatment response after CT-guided radiofrequency ablation of unresectable lung tumours by diffusion-weighted MRI: a pilot study. The British journal of radiology 2009;82(984):989-94.

185. Zhou R, Yu T, Feng C, Ma L, Wang Y, Li W, et al. [Diffusion-weighted imaging for assessment of lung cancer response to chemotherapy]. Zhongguo fei ai za zhi $=$ Chinese journal of lung cancer 2011;14(3):256-60.

186." Lin C, Itti E, Luciani A, Zegai B, Lin SJ, Kuhnowski F, et al. Whole-body diffusionweighted imaging with apparent diffusion coefficient mapping for treatment response assessment in patients with diffuse large B-cell lymphoma: pilot study. Investigative radiology 2011;46(5):341-9.

187. Marzolini M, Wong WL, Ardeshna K, Padhani A, D'Sa S. Diffusion-weighted MRI compared to FDG PET-CT in the staging and response assessment of Hodgkin lymphoma. British journal of haematology 2012;156(5):557.

188. Wu X, Kellokumpu-Lehtinen PL, Pertovaara H, Korkola P, Soimakallio S, Eskola H, et al. Diffusion-weighted MRI in early chemotherapy response evaluation of patients with diffuse large B-cell lymphoma--a pilot study: comparison with 2-deoxy-2fluoro- D-glucose-positron emission tomography/computed tomography. NMR in biomedicine 2011;24(10):1181-90.

189. Fenchel M, Konaktchieva M, Weisel K, Kraus S, Claussen CD, Horger M. Response assessment in patients with multiple myeloma during antiangiogenic therapy using arterial spin labeling and diffusion-weighted imaging: a feasibility study. Academic radiology 2010;17(11):1326-33.

190. Horger M, Weisel K, Horger W, Mroue A, Fenchel M, Lichy M. Whole-body diffusionweighted MRI with apparent diffusion coefficient mapping for early response monitoring in multiple myeloma: preliminary results. AJR American journal of roentgenology 2011;196(6):W790-5.

191. Kyriazi S, Collins DJ, Messiou C, Pennert K, Davidson RL, Giles SL, et al. Metastatic ovarian and primary peritoneal cancer: assessing chemotherapy response with diffusion-weighted MR imaging--value of histogram analysis of apparent diffusion coefficients. Radiology 2011;261(1):182-92.

192. Kyriazi S, Nye E, Stamp G, Collins DJ, Kaye SB, deSouza NM. Value of diffusion-weighted imaging for assessing site-specific response of advanced ovarian cancer to neoadjuvant chemotherapy: correlation of apparent diffusion coefficients with epithelial and stromal densities on histology. Cancer biomarkers : section A of Disease markers 2010;7(4):201-10. 
193. Sala E, Kataoka MY, Priest AN, Gill AB, McLean MA, Joubert I, et al. Advanced ovarian cancer: multiparametric MR imaging demonstrates response- and metastasisspecific effects. Radiology 2012;263(1):149-59.

194. Niwa T, Ueno M, Ohkawa S, Yoshida T, Doiuchi T, Ito K, et al. Advanced pancreatic cancer: the use of the apparent diffusion coefficient to predict response to chemotherapy. The British journal of radiology 2009;82(973):28-34.

195. Barrett T, Gill AB, Kataoka MY, Priest AN, Joubert I, McLean MA, et al. DCE and DW MRI in monitoring response to androgen deprivation therapy in patients with prostate cancer: a feasibility study. Magnetic resonance in medicine - 2012;67(3):778-85.

196. Messiou C, Collins DJ, Giles S, de Bono JS, Bianchini D, de Souza NM. Assessing response in bone metastases in prostate cancer with diffusion weighted MRI. European radiology 2011;21(10):2169-77.

197. Nemoto K, Tateishi $T$, Ishidate $T$. Changes in diffusion-weighted images for visualizing prostate cancer during antiandrogen therapy: preliminary results. Urologia internationalis 2010;85(4):421-6.

198. Song I, Kim CK, Park BK, Park W. Assessment of response to radiotherapy for prostate cancer: value of diffusion-weighted MRI at $3 \mathrm{~T}$. AJR American journal of roentgenology 2010;194(6):W477-82.

199. Curvo-Semedo L, Lambregts DM, Maas M, Thywissen T, Mehsen RT, Lammering G, et al. Rectal cancer: assessment of complete response to preoperative combined radiation therapy with chemotherapy--conventional MR volumetry versus diffusionweighted MR imaging. Radiology 2011;260(3):734-43.

200. Jang KM, Kim SH, Choi D, Lee SJ, Park MJ, Min K. Pathological correlation with diffusion restriction on diffusion-weighted imaging in patients with pathological complete response after neoadjuvant chemoradiation therapy for locally advanced rectal cancer: preliminary results. The British journal of radiology 2012;85(1017):e566-72.

201. Kim SH, Lee JY, Lee JM, Han JK, Choi BI. Apparent diffusion coefficient for evaluating tumour response to neoadjuvant chemoradiation therapy for locally advanced rectal cancer. European radiology 2011;21(5):987-95.

202. Lambrecht M, Vandecaveye V, De Keyzer F, Roels S, Penninckx F, Van Cutsem E, et al. Value of diffusion-weighted magnetic resonance imaging for prediction and early assessment of response to neoadjuvant radiochemotherapy in rectal cancer: preliminary results. International journal of radiation oncology, biology, physics 2012;82(2):863-70.

203. Lambregts DM, Beets GL, Maas M, Curvo-Semedo L, Kessels AG, Thywissen T, et al. Tumour ADC measurements in rectal cancer: effect of ROI methods on ADC values and interobserver variability. European radiology 2011;21(12):2567-74. 
204. Lambregts DM, Vandecaveye V, Barbaro B, Bakers FC, Lambrecht M, Maas M, et al. Diffusion-weighted MRI for selection of complete responders after chemoradiation for locally advanced rectal cancer: a multicenter study. Annals of surgical oncology 2011;18(8):2224-31.

205. Seehaus A, Vacaro C, Ocantos J, Varela A, Savluk L, Ojea Quintana G, et al. [Diffusionweighted MR imaging in patients with rectal cancer: our initial experience]. Acta gastroenterologica Latinoamericana 2011;41(3):199-207.

206. DeVries AF, Kremser C, Hein PA, Griebel J, Krezcy A, Ofner D, et al. Tumor microcirculation and diffusion predict therapy outcome for primary rectal

= carcinoma. International journal of radiation oncology, biology, physics 2003;56(4):958-65.

207. Lambrecht M, Deroose C, Roels S, Vandecaveye V, Penninckx F, Sagaert X, et al. The use of FDG-PET/CT and diffusion-weighted magnetic resonance imaging for response prediction before, during and after preoperative chemoradiotherapy for rectal cancer. Acta oncologica 2010;49(7):956-63.

208. Bajpai J, Gamnagatti S, Kumar R, Sreenivas V, Sharma MC, Khan SA, et al. Role of MRI in osteosarcoma for evaluation and prediction of chemotherapy response: correlation with histological necrosis. Pediatric radiology 2011;41(4):441-50.

209. Baunin C, Schmidt G, Baumstarck K, Bouvier C, Gentet JC, Aschero A, et al. Value of diffusion-weighted images in differentiating mid-course responders to chemotherapy for osteosarcoma compared to the histological response: preliminary results. Skeletal radiology 2012;41(9):1141-9.

210. Dudeck O, Zeile M, Pink D, Pech M, Tunn PU, Reichardt P, et al. Diffusion-weighted magnetic resonance imaging allows monitoring of anticancer treatment effects in patients with soft-tissue sarcomas. Journal of magnetic resonance imaging : JMRI 2008;27(5):1109-13.

211. Oka K, Yakushiji T, Sato H, Hirai T, Yamashita Y, Mizuta H. The value of diffusionweighted imaging for monitoring the chemotherapeutic response of osteosarcoma: a comparison between average apparent diffusion coefficient and minimum apparent diffusion coefficient. Skeletal radiology 2010;39(2):141-6.

212. Uhl M, Saueressig U, Koehler G, Kontny U, Niemeyer C, Reichardt W, et al. Evaluation of tumour necrosis during chemotherapy with diffusion-weighted MR imaging: preliminary results in osteosarcomas. Pediatric radiology 2006;36(12):1306-11.

213. Einarsdottir H, Karlsson M, Wejde J, Bauer HC. Diffusion-weighted MRI of soft tissue tumours. European radiology 2004;14(6):959-63.

214. Koh DM, Blackledge M, Collins DJ, Padhani AR, Wallace T, Wilton B, et al. Reproducibility and changes in the apparent diffusion coefficients of solid tumours treated with combretastatin A4 phosphate and bevacizumab in a two-centre phase I clinical trial. European radiology 2009;19(11):2728-38. 
215. Dirix P, Vandecaveye V, De Keyzer F, Stroobants S, Hermans R, Nuyts S. Dose painting in radiotherapy for head and neck squamous cell carcinoma: value of repeated functional imaging with (18)F-FDG PET, (18)F-fluoromisonidazole PET, diffusion-weighted MRI, and dynamic contrast-enhanced MRI. Journal of nuclear medicine : official publication, Society of Nuclear Medicine 2009;50(7):1020-7.

216. King AD, Mo FK, Yu KH, Yeung DK, Zhou H, Bhatia KS, et al. Squamous cell carcinoma of the head and neck: diffusion-weighted MR imaging for prediction and monitoring of treatment response. European radiology 2010;20(9):2213-20.

217. Vandecaveye V, Dirix P, De Keyzer F, de Beeck KO, Vander Poorten V, Roebben I, et = al. Predictive value of diffusion-weighted magnetic resonance imaging during chemoradiotherapy for head and neck squamous cell carcinoma. European radiology 2010;20(7):1703-14.

218. Vandecaveye V, Dirix P, De Keyzer F, Op de Beeck K, Vander Poorten V, Hauben E, et al. Diffusion-weighted magnetic resonance imaging early after chemoradiotherapy to monitor treatment response in head-and-neck squamous cell carcinoma. International journal of radiation oncology, biology, physics 2012;82(3):1098-107.

219. Kato H, Kanematsu M, Tanaka O, Mizuta K, Aoki M, Shibata T, et al. Head and neck squamous cell carcinoma: usefulness of diffusion-weighted MR imaging in the prediction of a neoadjuvant therapeutic effect. European radiology 2009;19(1):1039.

220. Kim S, Loevner L, Quon H, Sherman E, Weinstein G, Kilger A, et al. Diffusionweighted magnetic resonance imaging for predicting and detecting early response to chemoradiation therapy of squamous cell carcinomas of the head and neck. Clinical cancer research : an official journal of the American Association for Cancer Research 2009;15(3):986-94.

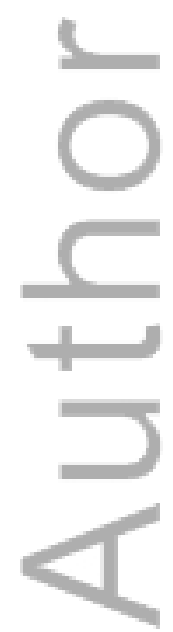

This article is protected by copyright. All rights reserved. 


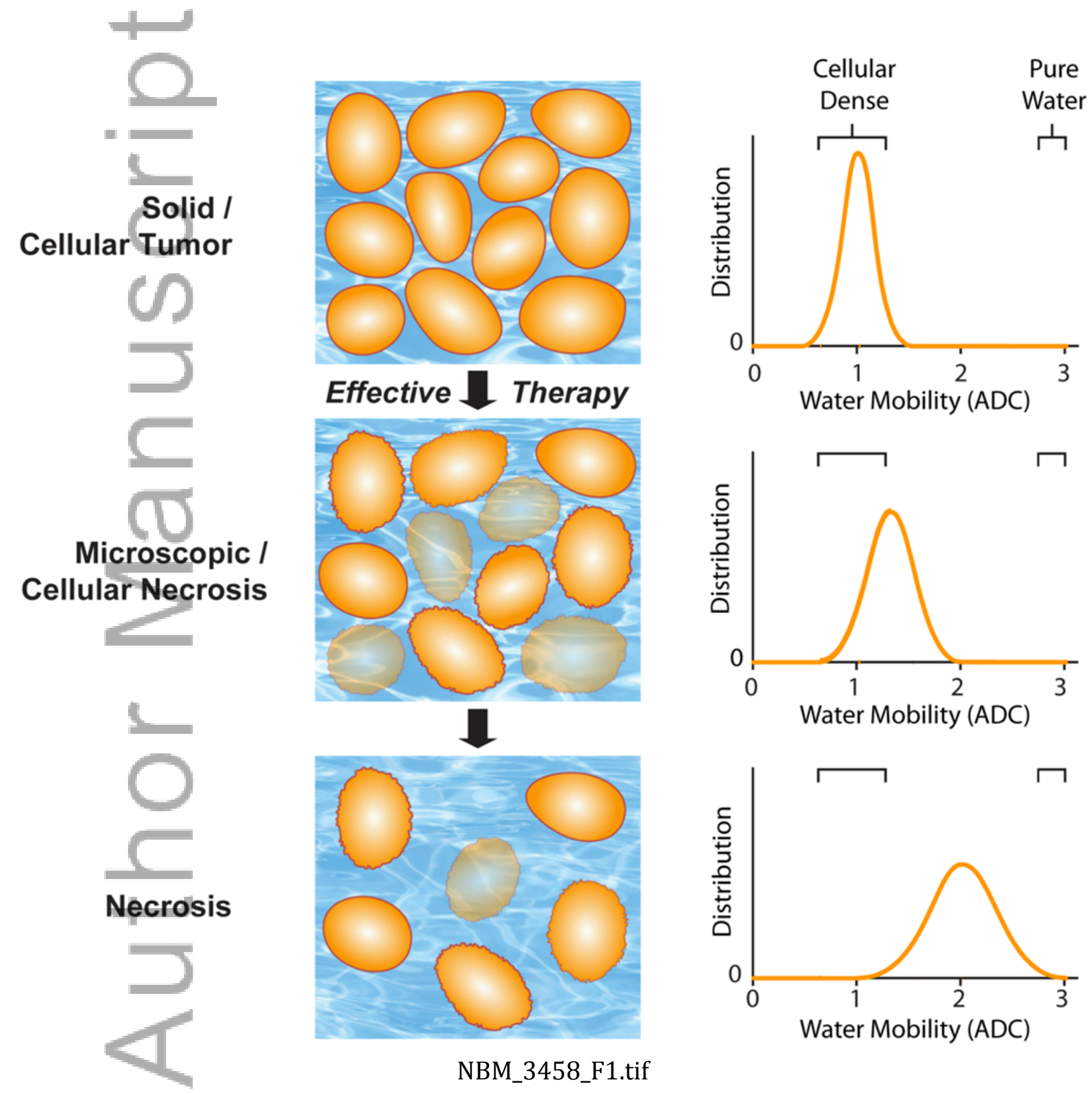

This article is protected by copyright. All rights reserved. 

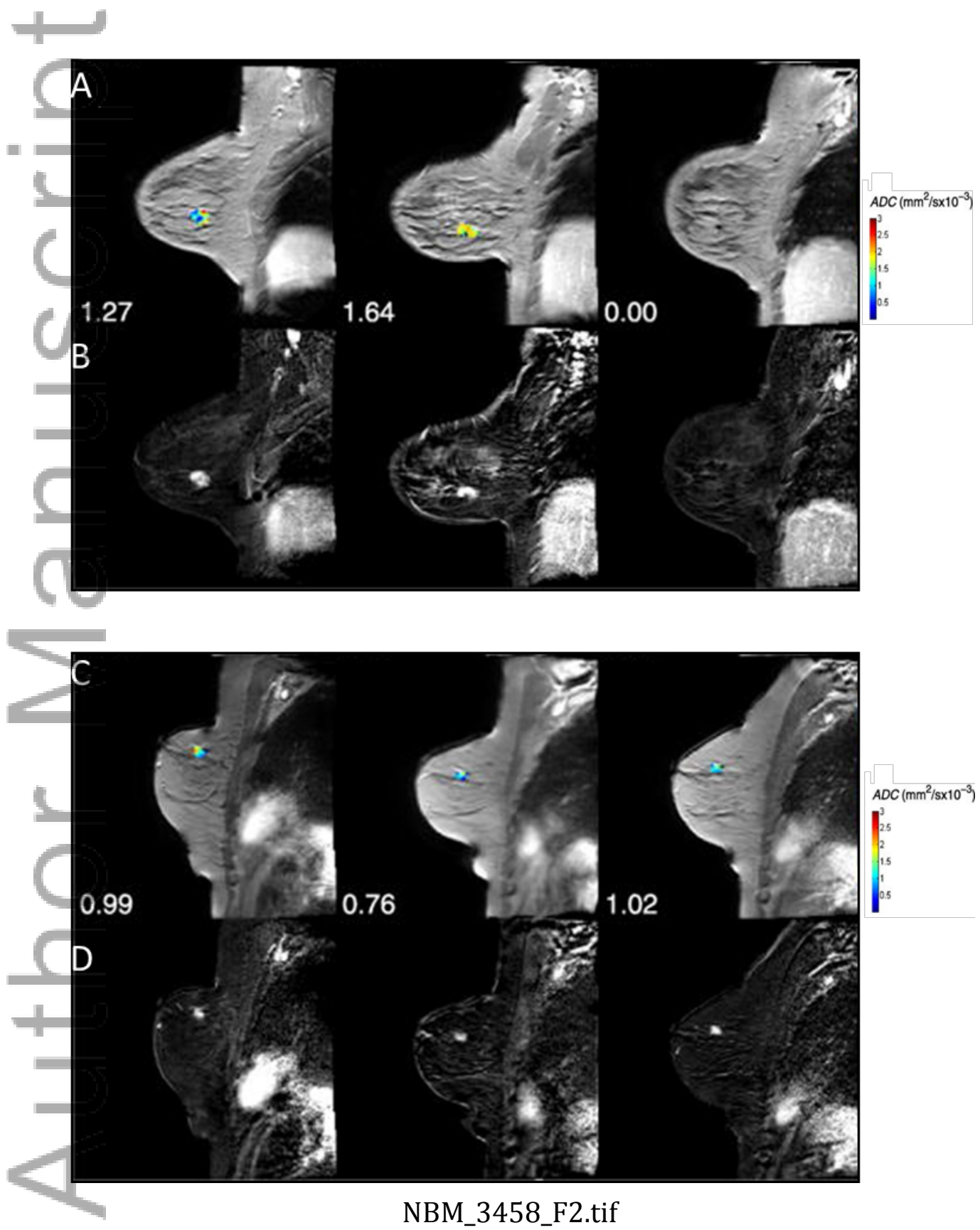

This article is protected by copyright. All rights reserved. 


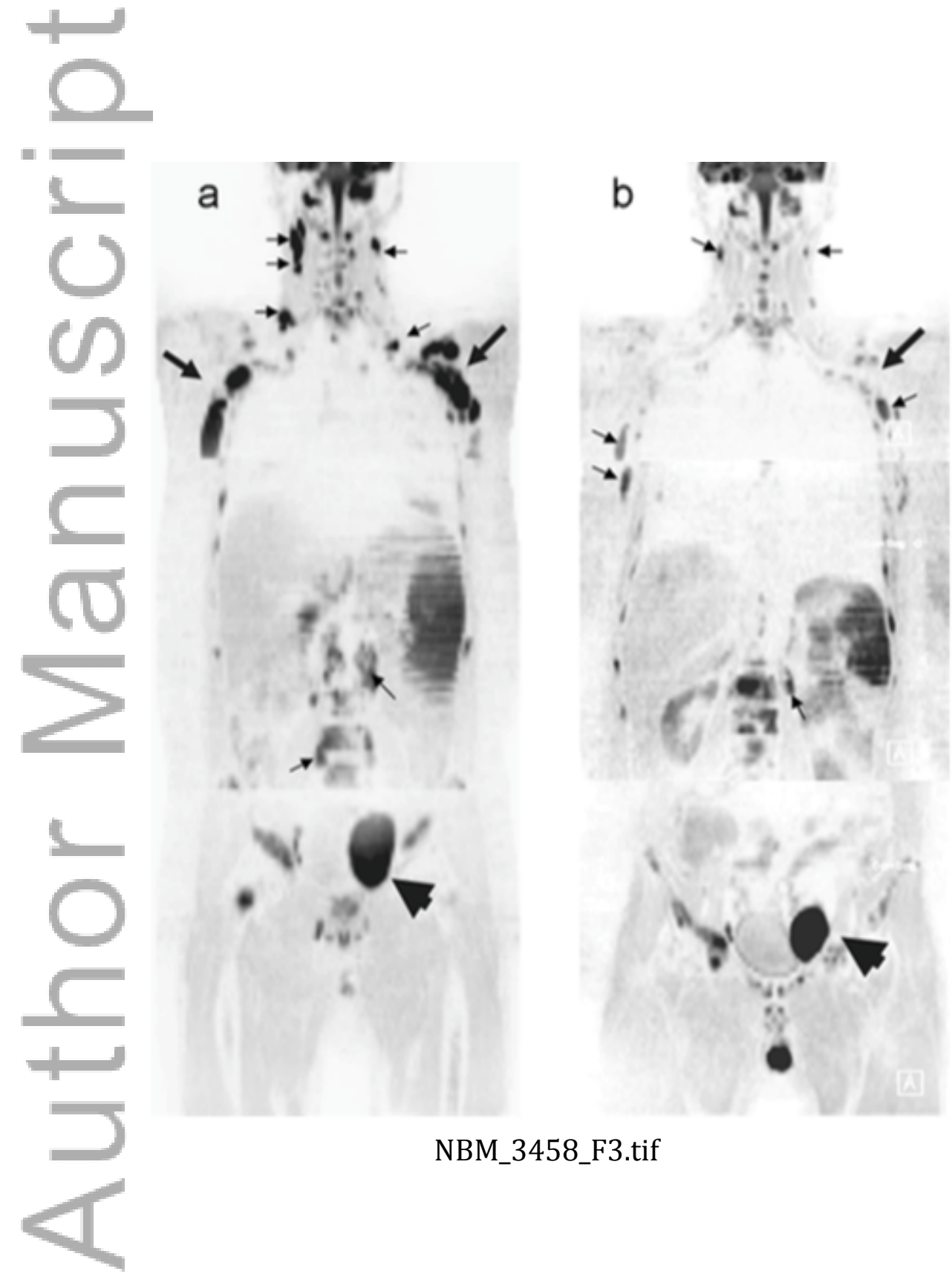

This article is protected by copyright. All rights reserved. 

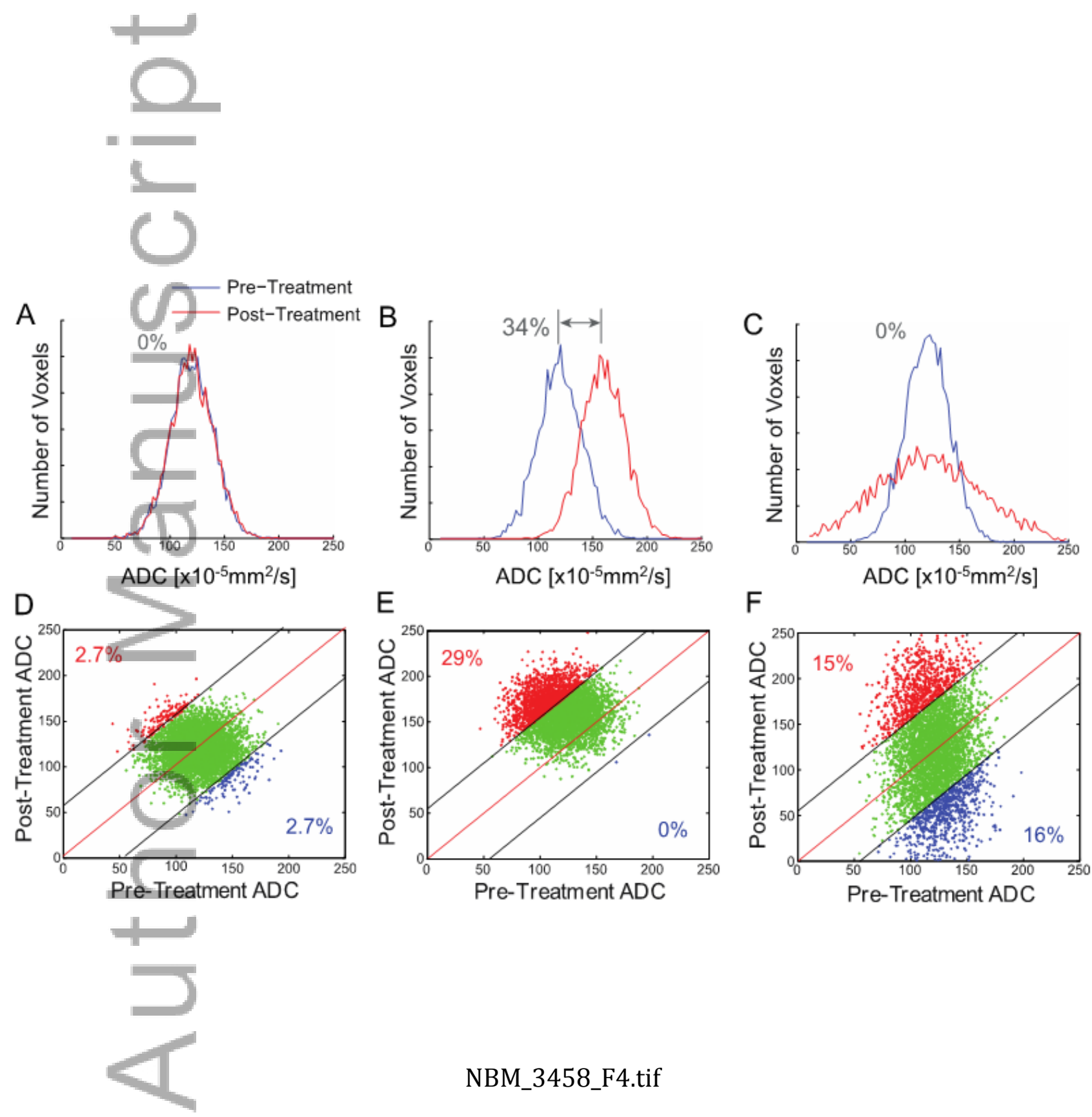

NBM_3458_F4.tif

This article is protected by copyright. All rights reserved. 


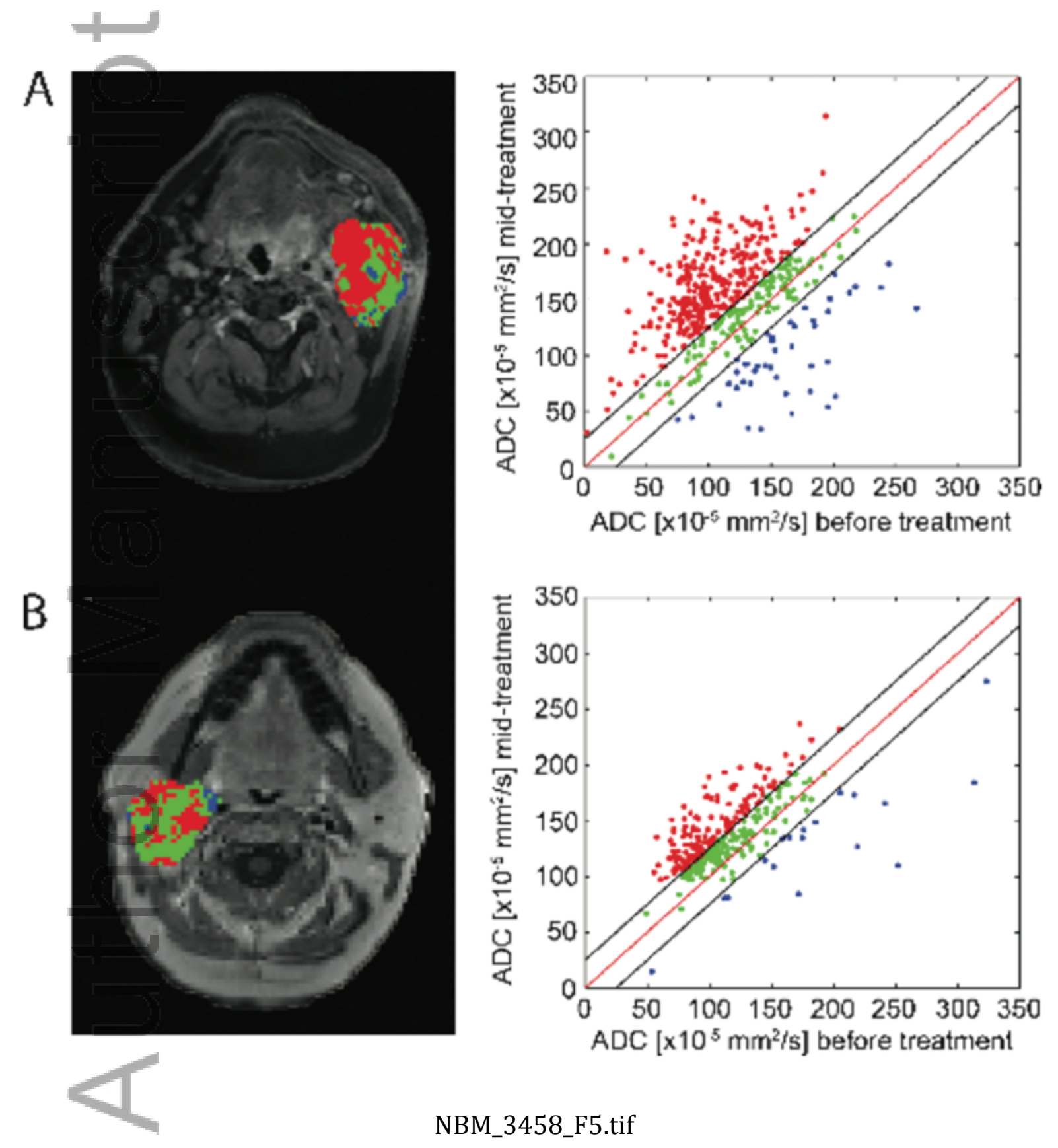

This article is protected by copyright. All rights reserved. 


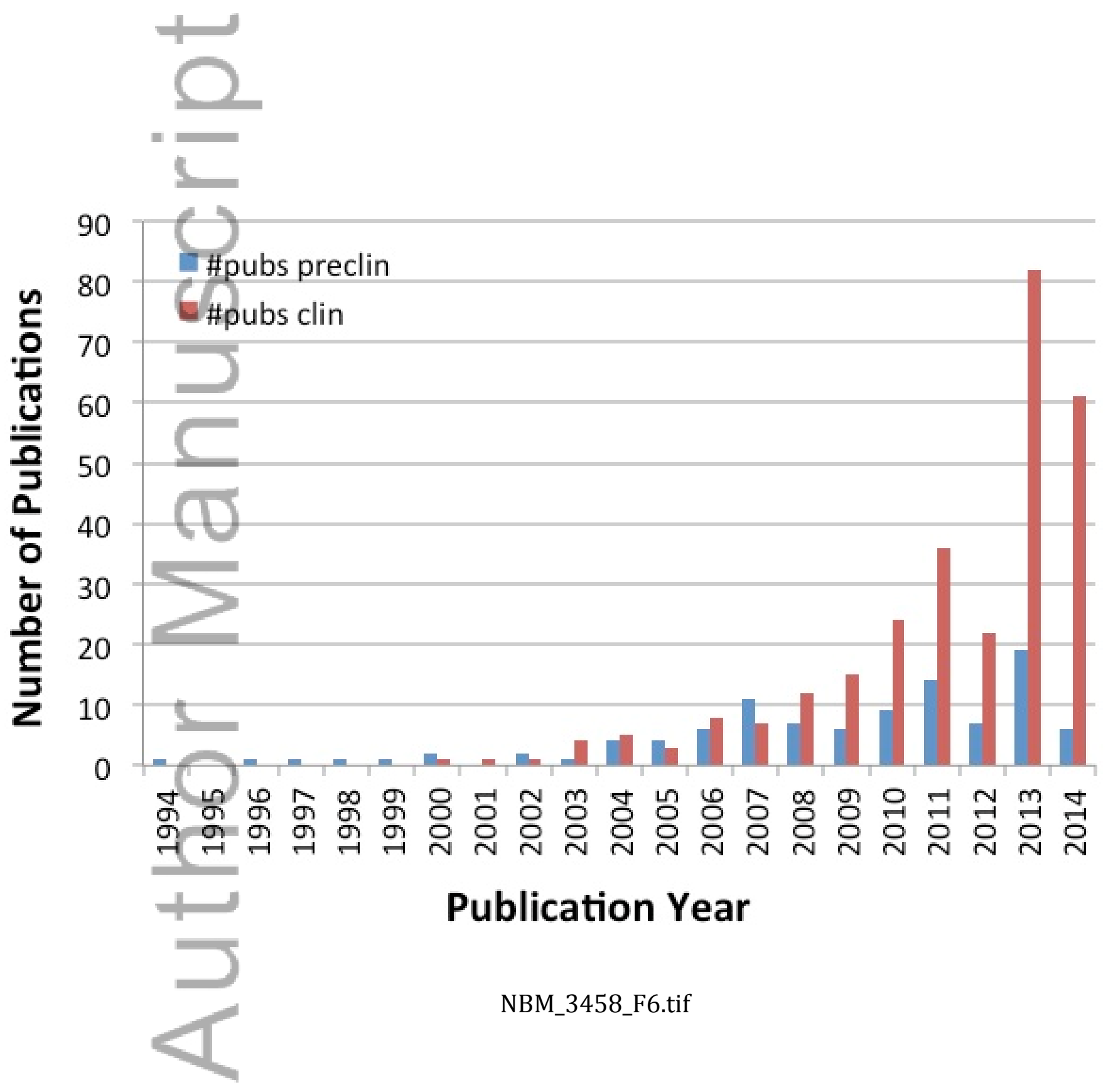

This article is protected by copyright. All rights reserved. 
DW-MRI is sensitive to cellular changes and has been extensively evaluated as a quantitative and early imaging biomarker of therapeutic response. DW-MR can be applied to many different solid tumors to detect changes in cellularity as measured by an early increase in the apparent diffusion coefficient (ADC) of water molecules within the lesion. An overview of DW-MRI acquisition protocols, quantitative image analysis approaches and an overview of applications implementing DW-MRI for early prediction of cancer treatment response are presented.

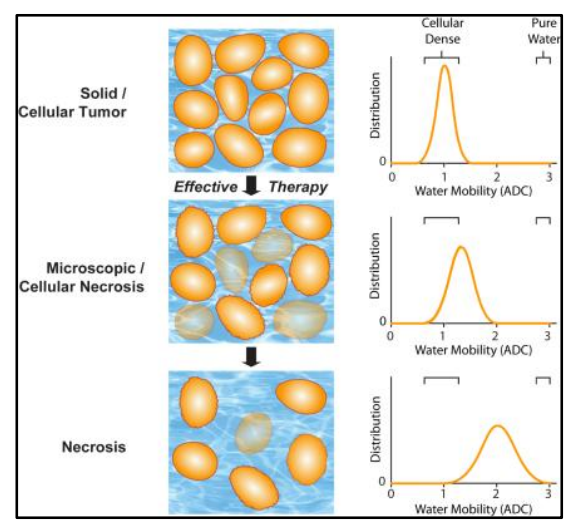

Diffusion MRI in Early Cancer

Therapeutic Response Assessment

C. J. Galbán, B. A. Hoff,

T. L. Chenevert and B. D. Ross* 